\title{
Sildenafil attenuates pulmonary inflammation and fibrin deposition, mortality and right ventricular hypertrophy in neonatal hyperoxic lung injury
}

\author{
Yvonne P de Visser ${ }^{1}$, Frans J Walther ${ }^{1,3}$, El Houari Laghmani ${ }^{1}$, \\ Hester Boersma ${ }^{1}$, Arnoud van der Laarse ${ }^{2}$ and Gerry TM Wagenaar*1
}

\begin{abstract}
Address: ${ }^{1}$ Department of Pediatrics, Division of Neonatology, Leiden University Medical Center, 2300 RC Leiden, the Netherlands, ${ }^{2}$ Department of Cardiology, Leiden University Medical Center, 2300 RC Leiden, the Netherlands and ${ }^{3}$ Department of Pediatrics, Los Angeles Biomedical Research Institute at Harbor-UCLA Medical Center, Torrance, CA 90502, USA

Email: Yvonne P de Visser - y.p.de_visser@lumc.nl; Frans J Walther - f.j.walther@lumc.nl; El Houari Laghmani - e.h.laghmani@lumc.nl; Hester Boersma - H.boersma@lumc.nl; Arnoud van der Laarse - A.van_der_laarse@lumc.nl; Gerry TM Wagenaar* - g.t.m.wagenaar@lumc.nl

* Corresponding author
\end{abstract}

Published: 29 April 2009

Respiratory Research 2009, 10:30 doi:10.1186/1465-9921-10-30
Received: 7 August 2008

Accepted: 29 April 2009

This article is available from: http://respiratory-research.com/content//0/I/30

(c) 2009 de Visser et al; licensee BioMed Central Ltd.

This is an Open Access article distributed under the terms of the Creative Commons Attribution License (http://creativecommons.org/licenses/by/2.0), which permits unrestricted use, distribution, and reproduction in any medium, provided the original work is properly cited.

\begin{abstract}
Background: Phosphodiesterase-5 inhibition with sildenafil has been used to treat severe pulmonary hypertension and bronchopulmonary dysplasia (BPD), a chronic lung disease in very preterm infants who were mechanically ventilated for respiratory distress syndrome.

Methods: Sildenafil treatment was investigated in 2 models of experimental BPD: a lethal neonatal model, in which rat pups were continuously exposed to hyperoxia and treated daily with sildenafil $(50-150 \mathrm{mg} / \mathrm{kg}$ body weight/day; injected subcutaneously) and a neonatal lung injury-recovery model in which rat pups were exposed to hyperoxia for 9 days, followed by 9 days of recovery in room air and started sildenafil treatment on day 6 of hyperoxia exposure. Parameters investigated include survival, histopathology, fibrin deposition, alveolar vascular leakage, right ventricular hypertrophy, and differential mRNA expression in lung and heart tissue.

Results: Prophylactic treatment with an optimal dose of sildenafil $(2 \times 50 \mathrm{mg} / \mathrm{kg} / \mathrm{day})$ significantly increased lung cGMP levels, prolonged median survival, reduced fibrin deposition, total protein content in bronchoalveolar lavage fluid, inflammation and septum thickness. Treatment with sildenafil partially corrected the differential mRNA expression of amphiregulin, plasminogen activator inhibitor-I, fibroblast growth factor receptor-4 and vascular endothelial growth factor receptor-2 in the lung and of brain and c-type natriuretic peptides and the natriuretic peptide receptors NPR-A, $-B$, and $-C$ in the right ventricle. In the lethal and injury-recovery model we demonstrated improved alveolarization and angiogenesis by attenuating mean linear intercept and arteriolar wall thickness and increasing pulmonary blood vessel density, and right ventricular hypertrophy (RVH).

Conclusion: Sildenafil treatment, started simultaneously with exposure to hyperoxia after birth, prolongs survival, increases pulmonary cGMP levels, reduces the pulmonary inflammatory response, fibrin deposition and $\mathrm{RVH}$, and stimulates alveolarization. Initiation of sildenafil treatment after hyperoxic lung injury and continued during room air recovery improves alveolarization and restores pulmonary angiogenesis and $\mathrm{RVH}$ in experimental BPD.
\end{abstract}




\section{Introduction}

Pharmacological and technical advances in neonatal intensive care medicine have greatly improved the survival and morbidity of premature infants. The preterm lung is highly susceptible to injury during resuscitation and mechanical ventilation and to pro-inflammatory mediators interfering with signaling required for normal late gestational lung development [1]. Preterm infants of $<30$ weeks of gestation and a birth weight of $<1,200 \mathrm{~g}$ are at high risk for perinatal lung injury, that can progress to chronic lung disease (bronchopulmonary dysplasia, $\mathrm{BPD})$. BPD is characterized by an arrest in alveolar and vascular lung development, complicated by inflammation, abnormal coagulation and fibrinolysis with intraalveolar fibrin accumulation, oxidative stress, and at later stages by pulmonary hypertension and right ventricular hypertrophy $[1,2]$.

Pharmacological treatment of BPD has relied upon systemic glucocorticoid administration, but has been refuted because of a higher incidence of neurological morbidity in long-term survivors. Theophylline, a non-selective phosphodiesterase (PDE) inhibitor, is widely used in neonatal intensive care to treat apnea of prematurity and wean preterm infants at risk for developing BPD from the ventilator, because it increases respiratory drive and has an immunomodulatory effect $[3,4]$. Since inflammation and unbalanced coagulation and fibrinolysis, leading to extravascular fibrin deposition in the lung, are two interrelated processes that play a pivotal role in the pathophysiology of inflammatory lung disease, we investigated whether the development of BPD can be interrupted by intervening in the vicious cycle of inflammation and coagulation. We have previously shown that anti-inflammatory agents, including the PDE4 inhibitors pentoxifylline, rolipram and piclamilast, and inhaled nitric oxide (NO) reduce fibrin deposition, pulmonary inflammation and prolong survival in rats with neonatal hyperoxic lung injury [5-7], a suitable in vivo model for experimental BPD [8]. PDEs exert their biological function by inactivating the intracellular messenger cAMP and CGMP by hydrolysis $[9,10]$. PDE5, a cGMP-specific inactivator, is expressed in smooth muscle cells, vascular endothelium, and platelets [9]. Inhibition of PDE5 increases intracellular cGMP levels. Inhibition of PDE5 promotes alveolar growth and angiogenesis, and attenuates inflammation and airway reactivity in animal models [11-15]. PDE5 inhibition also improves pulmonary vascular physiology in infants with persistent pulmonary hypertension, which may lead to prevention of right ventricular hypertrophy (RVH) $[16,17]$.

To elucidate the role of PDE5 inhibition in the vicious circle of inflammation and coagulation in neonatal hyperoxic lung disease, we investigated the effect of sildenafil, a selective PDE5 inhibitor [18], using two different treatment strategies: a prophylactic strategy in a lethal model and a more clinically relevant strategy in which treatment was started after injury was induced in a non-lethal lung injury-recovery model. In the lethal model we show that sildenafil administration throughout the experimental period reduces inflammation, attenuates pulmonary fibrin deposition, improves alveolarization and angiogenesis, prevents RVH and prolongs survival of rat pups with hyperoxia-induced BPD. In the lung injury-recovery model we show that sildenafil treatment improves alveolarization and restores angiogenesis and $\mathrm{RVH}$ by reducing MLI, arteriolar wall thickness and increasing pulmonary vessel density and reducing right ventricular free wall thickness in rat pups with hyperoxia-induced BPD.

\section{Materials and methods Animals}

The research protocol was approved by the Institutional Animal Care and Use Committee of the Leiden University Medical Center. Timed-pregnant Wistar rats were kept in a $12 \mathrm{~h}$ dark/light cycle and fed a standard chow diet (Special Diet Services, Witham, Essex, England) ad libitum. Breeding pairs were allowed access for one hour on the day female rats showed very specific sexual behaviour: lordosis, hopping and air-flapping. After a gestation of approximately $21^{1 / 2}$ days pregnant rats were killed by decapitation (spontaneous birth occurs 22 days after conception) and pups were delivered by hysterectomy through a median abdominal incision to ensure that the delay in birth between the first and the last pup is only 5 min. Immediately after birth, pups were dried and stimulated. Pups from four litters were pooled and distributed over two experimental groups: the oxygen $\left(\mathrm{O}_{2}\right)$ and the oxygen-sildenafil (sildenafil) group, and a room airexposed (RA) control group. Litter size was 12 pups per litter in the experimental groups. Pups were kept in a transparent $50 \times 50 \times 70 \mathrm{~cm}$ Plexiglas chamber for 10 days or until death occurred (survival experiments). In this way influences of the birth process within and between litters can be avoided and exposure to hyperoxia can be started within 30 min after birth. Pups were fed by lactating foster dams, which were rotated daily to avoid oxygen toxicity. Foster dams were exposed to $100 \%$ oxygen for $24 \mathrm{~h}$ and next to room air for $48 \mathrm{~h}$. The oxygen concentration was kept at $100 \%$ using a flow of $2.5 \mathrm{~L} / \mathrm{min}$. Oxygen concentrations were monitored daily with an oxygen sensor (Drägerwerk AG, Lübeck, Germany). Weight, evidence of disease, and mortality were also checked daily.

\section{Lethal neonatal hyperoxia model}

In this model neonatal lung injury was induced by continuous exposure to $100 \%$ oxygen for 10 days. Starting on day 2, hyperoxia-exposed pups were injected daily subcutaneously with a $0.5 \mathrm{~mL}$ syringe (U-100 Micro-Fine insu- 
lin 29G syringe, Becton Dickinson, Franklin Lakes, NJ, USA) at the lower back. Pups received either $150 \mu \mathrm{L}$ sildenafil citrate (a gift from Pfizer Limited, Sandwich, Kent, $\mathrm{UK}$ ) in $0.9 \%$ saline or $150 \mu \mathrm{L} 0.9 \%$ saline (age-matched control). In a pilot experiment in which rats were treated with 50-150 mg/kg/day sildenafil (25-75 mg/kg twice a day) under hyperoxia, we found that pups treated with $150 \mathrm{mg} / \mathrm{kg} /$ day sildenafil showed severe growth retardation and increased mortality. Therefore, experiments were performed with 50 and $100 \mathrm{mg} / \mathrm{kg} /$ day sildenafil. Separate experiments were performed for (1) survival studies, (2) collection of lung and heart tissue for fibrin deposition and RT-PCR, (3) histology, and (4) collection of bronchoalveolar lavage fluid.

\section{Neonatal lung injury-recovery model}

The effect of sildenafil on lung injury and recovery was investigated by exposing newborn rat pups to hyperoxia for 9 days, followed by recovery in room air for 9 days. After 6 days of exposure to hyperoxia daily subcutaneous injections with $100 \mathrm{mg} / \mathrm{kg} /$ day sildenafil were started and continued throughout the 9-day recovery period in room air. Lung and heart tissue was collected for histology at the end of the 9-day hyperoxia period and after the 9-day recovery period in room air.

\section{Tissue preparation}

Pups were anesthetized with an intraperitoneal injection of ketamine $(25 \mathrm{mg} / \mathrm{kg}$ body weight; Nimatek, Eurovet Animal Health BV, Bladel, The Netherlands) and xylazine (50 mg/kg body weight; Rompun, Bayer, Leverkusen, Germany) on day 10. To avoid postmortem fibrin deposition in the lungs, heparin (100 units; Leo Pharma, Breda, The Netherlands) was injected intraperitoneally. After $5 \mathrm{~min}$, pups were exsanguinated by transection of the abdominal blood vessels. The thoracic cavity was opened, and the lungs and heart were removed, snap-frozen in liquid nitrogen, and stored at $-80^{\circ} \mathrm{C}$ until analysis by real-time RT-PCR, fibrin deposition or the cyclic GMP assay. For histology studies, the trachea was cannulated (Bioflow 0.6 $\mathrm{mm}$ intravenous catheter, Vygon, Veenendaal, The Netherlands), and the lungs and heart were fixed in situ via the trachea cannula with buffered formaldehyde (4\% paraformaldehyde in PBS, pH 7.4) at $25 \mathrm{~cm} \mathrm{H}_{2} \mathrm{O}$ pressure for 5 min. Lungs and hearts were removed, fixed (additionally) in formaldehyde for $24 \mathrm{~h}$ at $4^{\circ} \mathrm{C}$, and embedded in paraffin after dehydration in a graded alcohol series and xylene. To quantify the degree of right ventricular hypertrophy (RVH), hearts were harvested, followed by the removal of left and right atria. Hereafter the right ventricular free wall (RV) was dissected, weighed separately from the interventricular septum (IVS) and left ventricle (LV), frozen immediately in liquid nitrogen, and stored at $-80^{\circ} \mathrm{C}$ for real time RT-PCR. As an indicator of RVH the weight ratio RV/(LV + IVS) was calculated.

\section{Bronchoalveolar lavages}

Pups were anesthetized with an intraperitoneal injection of ketamine and xylazine and injected intraperitoneally with heparin on day 10. A cannula (Bioflow $0.6 \mathrm{~mm}$ intravenous catheter, Vygon, Veenendaal, The Netherlands) was positioned in the trachea, and the pups were exsanguinated by transection of the abdominal blood vessels. Lungs were slowly lavaged two times with $500 \mu \mathrm{L} 0.15 \mathrm{M}$ $\mathrm{NaCl}, 1 \mathrm{mM}$ EDTA (pH 8.0), without opening the thorax. Samples were pooled, stored temporarily at $4{ }^{\circ} \mathrm{C}$ and centrifuged for $10 \mathrm{~min}$ at 5,000 rpm. Supernatants were stored at $-20^{\circ} \mathrm{C}$ until further use.

\section{Histology}

Paraffin sections $(5 \mu \mathrm{m})$ were cut and mounted onto SuperFrost plus-coated slides (Menzel, Braunschweig, Germany). After deparaffinization, lung sections were stained with hematoxylin and eosin (HE) or with monoclonal anti-ED-1 antibody that specifically recognizes rat monocytes and macrophages [19], with polyclonal (rabbit) anti-myeloperoxidase (MPO) antibody [20], with monoclonal anti-alpha smooth muscle actin (ASMA) to visualize the pulmonary medial arterial walls or with polyclonal (rabbit) anti-von Willebrand Factor (vWF) as a marker for pulmonary blood vessels. Heart sections were stained with hematoxylin and eosin or with polyclonal (rabbit) anti-tenascin-C antibody, as an indicator for cardiac tissue damage [21]. For immunohistochemistry, sections were incubated with $0.3 \% \mathrm{H}_{2} \mathrm{O}_{2}$ in methanol to block endogenous peroxidase activity. After a graded alcohol series, sections were boiled in $0.01 \mathrm{M}$ sodium citrate ( $\mathrm{pH} 6.0$ ) for $10 \mathrm{~min}$. Sections were incubated overnight with monoclonal anti-ED-1, polyclonal anti-MPO (Thermo Fisher Scientific, Fremont, CA, USA), monoclonal anti-ASMA (A2547, Sigma-Aldrich, St. Louis, MO, USA), polyclonal anti-vWF (A0082, Dako Cytomation, Glostrup, Denmark) or polyclonal anti-tenascin-C antibody (SC-20932, Santa Cruz Biotechnology, Santa Cruz, CA, USA), stained with EnVision-HRP (Dako, Glostrup, Denmark) using NovaRed (Vector, Burlingame, CA, USA) as chromogenic substrate, and counterstained briefly with hematoxylin. For morphometry of the lung, an eye piece reticle with a coherent system of 21 lines and 42 points (Weibel type II ocular micrometer; Paes, Zoeterwoude, The Netherlands) was used. Mean linear intercept (MLI), an indicator of mean alveolar diameter, was assessed in 10 non-overlapping fields at a $200 \times$ magnification in one HE-section for each animal. The density of ED-1 positive monocytes and macrophages or MPO-positive neutrophilic granulocytes was determined by counting the number of cells per field. Fields containing large blood vessels or bronchioli were excluded from the analysis. Results were expressed as cells per $\mathrm{mm}^{2}$. Per experimental animal 20 fields in one section were studied at a $400 \times$ magnification. Pulmonary alveolar septum thickness was 
assessed in HE-stained lung sections at a $400 \times$ magnification by averaging 100 measurements per 10 representative fields. Capillary density was assessed in lung sections stained for vWF at a $200 \times$ magnification by counting the number of vessels per field. At least 10 representative fields per experimental animal were investigated. Results were expressed as number of vessels per field. Pulmonary arteriolar wall thickness was assessed in lung sections stained for ASMA at a $1000 \times$ magnification by averaging at least 10 vessels with a diameter of less than $15 \mu \mathrm{m}$ per animal. Fields containing large blood vessels or bronchioli were excluded from the analysis. Thickness of the right and left ventricular free walls and interventricular septum (IVS) was assessed in a transversal section taken halfway the long axis at a $40 \times$ magnification by averaging 6 measurements per structure. For morphometric studies in lung and heart at least 6 rat pups per experimental group were studied. Quantitative morphometry was performed by two independent researchers blinded to the treatment strategy.

\section{Fibrin detection assay}

Fibrin deposition was detected in lung homogenates by Western blotting as described previously [8]. Tissue samples, dissolved in reducing sample buffer $(10 \mathrm{mM}$ Tris $\mathrm{pH}$ $7.5,2 \%$ SDS, $5 \%$ glycerol, $5 \% \beta$-mercaptoethanol, and 0.4 $\mathrm{mg} / \mathrm{mL}$ bromophenol blue) were subjected to SDS-PAGE (7.5\%; 5\% stacking) and blotted onto PVDF membrane (Immobilon-P, Millipore, Bredford, MA, USA). The 56$\mathrm{kDa}$ fibrin $\beta$-chains were detected with monoclonal 59D8 (Oklahoma Medical Research Foundation, Oklahoma City, OK, USA), which specifically recognizes $\beta$-fibrin $[8,22]$, using ECL plus Western blotting detection system and Hyperfilm ECL (Amersham Biosciences, Arlington Heights, IL, USA). Exposures were quantified with a BioRad GS-800 calibrated densitometer using the Quantity One, version 4.4.1 software package (Bio-Rad, Veenendaal, the Netherlands). Fibrin deposition was quantified in lungs of at least ten rats per experimental group using rat fibrin as a reference.

\section{Cyclic GMP assay}

Lung tissue samples were homogenized in 10 volumes of $5 \%$ trichloroacetic acid (TCA) at $4{ }^{\circ} \mathrm{C}$. Samples were centrifuged at $1,500 \mathrm{~g}$ for 10 minutes. TCA was extracted from the supernatant by adding 5 volumes of water-saturated ether for 3 times. Residual ether was removed from the aqueous layer by heating at $70^{\circ} \mathrm{C}$ for 10 minutes. Cyclic GMP was detected in non-acetylated samples using a cyclic GMP EIA Kit (581021, Cayman Chemical Company, Ann Arbor, MI, USA) according to manufacturer's instructions.

\section{Real-time $R$ T-PCR}

Total RNA was isolated from lung and heart tissue homogenates using guanidium-phenol-chloroform extraction and isopropanol precipitation (RNA-Bee, TelTest Inc, Bio-Connect BV, Huissen, the Netherlands). The RNA sample was dissolved in RNase-free water and quantified spectrophotometrically. The integrity of the RNA was studied by gel electrophoresis on a $1 \%$ agarose gel, containing ethidium bromide. Samples did not show degradation of ribosomal RNA by visual inspection under ultraviolet light. First-strand cDNA synthesis was performed with the SuperScript Choice System (Life Technologies, Breda, the Netherlands) by oligo(dT)12-18 priming as described previously [8]. For real-time quantitative PCR, $1 \mu \mathrm{L}$ of first-strand CDNA diluted 1:10 in RNase-free water was used in a total volume of $25 \mu \mathrm{L}$, containing $12.5 \mu \mathrm{L} 2 \times$ SYBR Green PCR Master Mix (Applied Biosystems, Foster City, CA, USA) and 200 ng of each primer. Primers, designed with the Primer Express software package (Applied Biosystems), are listed in Table 1. Hyperoxia-induced lung injury induces alterations in inflammation, coagulation, fibrinolysis, alveolar enlargement, and edema. Therefore, we studied differential

Table I: Sequences of oligonucleotides used as forward and reverse primers for real-time RT-PCR.

\begin{tabular}{|c|c|c|}
\hline Gene Product & Forward Primer & Reverse Primer \\
\hline Amphiregulin & 5'-TTTCGCTGGCGCTCTCA-3' & 5'-TTCCAACCCAGCTGCATAATG-3' \\
\hline ANP & 5'-CCAGGCCATATTGGAGCAAA-3' & 5'-AGGTTCTTGAAATCCATCAGATCTG-3' \\
\hline BNP & 5'-GAAGCTGCTGGAGCTGATAAGAG-3' & 5'-TGTAGGGCCTTGGTCCTTTG-3' \\
\hline CNP & 5'-AGGCAGCTGGTGGCAATC-3' & 5'-GCGATCGGTCTCCCTTGAG-3' \\
\hline FGFR4 & 5'-GTTGGCACGCAGCTCCTT-3' & 5'-GCAGGACCTTGTCCAGAGCTT-3' \\
\hline IL-6 & 5'-ATATGTTCTCAGGGAGATCTTGGAA-3' & 5'-TGCATCATCGCTGTTCATACAA-3' \\
\hline NPR-A & 5'-CCTCCTGACGTCCCTAAATGTG-3' & 5'-CCAGTGTGGAAAAGTGGTCTTG-3' \\
\hline NPR-B & 5'-TGAGCAAGCCACCCACTTC-3' & 5'-CAGCGGGCCGCAGATATA-3' \\
\hline NPR-C & 5'-ACCAACAGCTCTCCTTGCAAA-3' & 5'-AGGGCCCCCACAACAATT-3' \\
\hline PAl-I & 5'-AGCTGGGCATGACTGACATCT-3' & 5'-GCTGCTCTTGGTCGGAAAGA-3' \\
\hline $\mathrm{TF}$ & 5'-CCCAGAAAGCATCACCAAGTG-3' & 5'-TGCTCCACAATGATGAGTGTT-3' \\
\hline VEGFR2 & 5'-CCACCCCAGAAATGTACCAAAC-3' & 5'-AAAACGCGGGTCTCTGGTT-3' \\
\hline$\beta$-actin & 5'-TTCAACACCCCAGCCATGT-3' & 5'-AGTGGTACGACCAGAGGCATACA-3' \\
\hline
\end{tabular}


expression of key genes of these pathways, previously characterized in this rat model for experimental BPD [8], in lungs of pups exposed to room air, $100 \%$ oxygen, or $100 \%$ oxygen with $100 \mathrm{mg} / \mathrm{kg} /$ day sildenafil on postnatal day 10. PCR reactions consisting of $95^{\circ} \mathrm{C}$ for $10 \mathrm{~min}(1$ cycle), $94^{\circ} \mathrm{C}$ for $15 \mathrm{~s}$, and $60^{\circ} \mathrm{C}$ for $1 \mathrm{~min}$ ( 40 cycles), were performed on an ABI Prism 7900 HT Fast Real Time PCR system (Applied Biosystems) of the Leiden Genome Technology Center (Leiden, The Netherlands). Data were analyzed with the ABI Prism 7900 sequence detection system software (version 2.2) and quantified with the comparative threshold cycle method with $\beta$-actin as a housekeeping gene reference [23]. In a DNA array experiment we demonstrated that $\beta$-actin was not differentially expressed in lungs of hyperoxic rat pups compared to room air controls [8]. In addition $\beta$-actin was not differentially expressed in left and right ventricle in both control and experimental rat pups. In the heart samples mRNA expression in the RV was quantified relative to the expression in the LV and IVS.

\section{Protein assay}

Total protein concentration was measured in bronchoalveolar lavage fluid (BALF) using the Dc protein assay (BioRad, Veenendaal, the Netherlands), according to the manufacturer's instructions with bovine serum albumin, fraction V (Roche Diagnostics, Almere, The Netherlands) as a standard. The detection limit was $31 \mu \mathrm{g} / \mathrm{mL}$.

\section{Statistical analysis}

Values are expressed as mean \pm SEM. Differences between groups (> 3) were analyzed with analysis of variance
(ANOVA), followed by Tukey's multiple comparison test. For comparison of survival curves, Kaplan-Meier analysis followed by a log rank test was performed. Differences at $p$ values $<0.05$ were considered statistically significant.

\section{Results \\ Lethal neonatal hyperoxia model \\ Fibrin deposition}

Because fibrin deposition is a sensitive marker for tissue damage in hyperoxia-induced neonatal lung disease, pulmonary fibrin deposition was studied in homogenates as a read-out for lung damage using Western blot analysis (Figure 1A) and quantified after treatment with two different sildenafil concentrations (50 and $100 \mathrm{mg} / \mathrm{kg} /$ day; Figure $1 \mathrm{~B}$ ). Fibrin deposition was at reference levels during normal neonatal pulmonary development on day 10 (18.4 $\pm 1.8 \mathrm{ng}$ fibrin/mg tissue) and increased more than 13 -fold to $239 \pm 34.8 \mathrm{ng}$ fibrin/mg tissue in lungs of pups exposed to $100 \%$ oxygen for 10 days $(p<0.001)$. Compared to oxygen-exposed controls, sildenafil treatment attenuated fibrin deposition in a concentration-dependent way by $62.5 \%$ to $89.8 \pm 10.3 \mathrm{ng}$ fibrin/mg tissue for $100 \mathrm{mg} / \mathrm{kg} /$ day sildenafil $(p<0.05)$. Because $100 \mathrm{mg} / \mathrm{kg} /$ day of sildenafil was the most effective dose, additional experiments were limited to this dosage.

\section{Cyclic GMP}

To establish that sildenafil is a specific cyclic GMP dependent PDE inhibitor cyclic GMP levels were determined in lung tissue homogenates (Figure 1C). Exposure to hyperoxia for 10 days did not change cyclic GMP levels in lung homogenates compared to room air controls.
A

\section{Fibrin Standards}

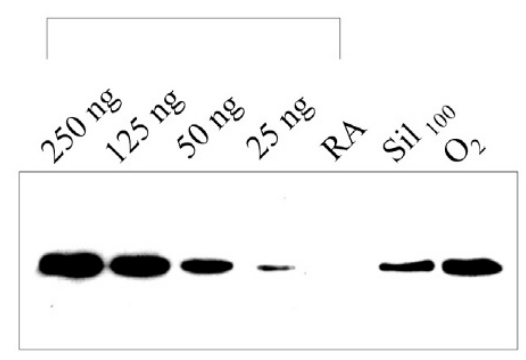

B

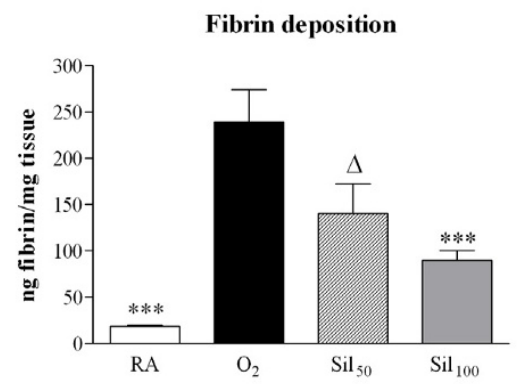

C

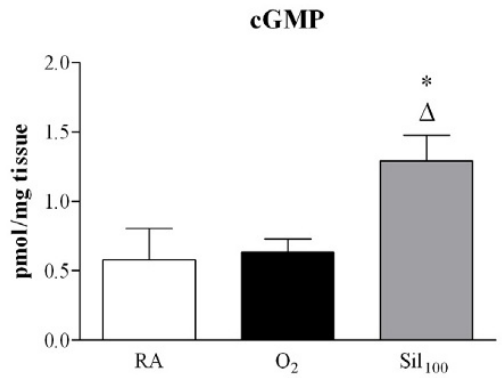

Figure I

Western blot analysis of fibrin deposition in lung homogenates of rat pups exposed to room air (RA), oxygen $\left(\mathrm{O}_{2}\right)$ and $\mathrm{O}_{2}$ in combination with $100 \mathrm{mg} / \mathrm{kg} / \mathrm{day}$ of sildenafil (Sil ${ }_{100}$ ) for 10 days (panel A). Panel B shows quantification of fibrin deposition in lung homogenates on day 10. Experimental groups include room air-exposed controls (RA, white bar), age-matched $\mathrm{O}_{2}$-exposed controls $\left(\mathrm{O}_{2}\right.$, black bar) and sildenafil-treated rat pups (50 mg/kg/day: Sil ${ }_{50}$, striped bar; $100 \mathrm{mg} /$ kg/day: Sil ${ }_{100}$, gray bar) under hyperoxia. Quantification of cyclic GMP in lung homogenates (panel C) in room air-exposed littermates (white bars), $\mathrm{O}_{2}$-exposed control pups (black bars) and $100 \mathrm{mg} / \mathrm{kg} /$ day sildenafil-treated pups (Sil ${ }_{100}$, gray bars). Data are expressed as mean \pm SEM of at least 6 pups per experimental group. $*_{p}<0.05$ and $*_{*} * p<0.00$ I versus age-matched $\mathrm{O}_{2}-$ exposed controls. ${ }^{\Delta} p<0.05$ versus room air-exposed controls. 
Treatment with sildenafil resulted in a significant increase in cyclic GMP by $102 \%(p<0.05)$ compared to oxygenexposed controls.

\section{Growth and survival}

At birth, on postnatal day 1, mean body weight of the rat pups was $5.0 \pm 0.18 \mathrm{~g}$ (Figure $2 \mathrm{~A}$ ). Body weight increased to approximately 8 grams on day 5 in oxygen exposed pups and room air controls. Hereafter, room air control pups grew slightly faster than oxygen-exposed pups. Growth of pups treated with $100 \mathrm{mg} / \mathrm{kg} /$ day sildenafil was not different from oxygen-exposed controls. Median survival of oxygen-exposed controls was 12 days and was prolonged with 4 days in pups treated with $100 \mathrm{mg} / \mathrm{kg} /$ day sildenafil and hyperoxia (Figure $2 \mathrm{~B} ; p<0.001$ ). After 13 days of oxygen exposure, $92 \%$ of the controls and only $25 \%$ of the sildenafil-treated pups had died. Room airexposed pups did not show signs of illness or mortality during the first 4 weeks after birth.

\section{Lung histology}

Lung development proceeds from the saccular stage at birth towards the alveolar stage on day 10 (Figure 3A). Oxygen exposure for 10 days resulted in edema, a reduction in pulmonary vessel density (Figure 3, panels B and D), a heterogeneous distribution of enlarged air-spaces with increased mean linear intercept (Figure 3E), which were surrounded by septa with increased thickness (Figure
3F) and an increase in pulmonary arteriolar medial wall thickness (Figure 3, panels $\mathrm{H}$ and $\mathrm{J}$ ). Sildenafil treatment improved alveolarization and angiogenesis during hyperoxia exposure by increasing pulmonary vessel density (47.9\%, $p<0.01$; Figure 3, panels C and D), decreasing mean linear intercept $(12.5 \%, p<0.001$; Figure $3 \mathrm{E})$, thinning of alveolar septa (34.2\%, $p<0.01$; Figure $3 F)$ and reducing arteriolar medial wall thickness $(38.8 \%, p<$ 0.001 ; Figure 3, panels I and J) compared to oxygen exposure for 10 days.

Hyperoxia led to a massive inflammatory reaction, characterized by an overwhelming influx of inflammatory cells, including macrophages (Figure 4B) and neutrophils (Figure 4E), compared to room air-exposed controls (Figure 4, panels A and D). Resident ED-1-positive monocytes and macrophages were present at 548 cells per $\mathrm{mm}^{2}$ in septa and alveoli of control lungs, whereas lungs of oxygenexposed pups contained 2.9 times as many $(p<0.001$; Figure $4 \mathrm{G})$. Sildenafil treatment reduced the influx of ED-1positive cells by $38.7 \%(p<0.001$; Figure 4 , panels $\mathrm{C}$ and $\mathrm{G})$ compared to oxygen-exposed controls. Resident MPOpositive neutrophils were present at 68 cells per $\mathrm{mm}^{2}$ in septa and alveoli of control lungs, whereas lungs of oxygen-exposed pups contained 7.3 times as many $(p<0.001$; Figure $4 \mathrm{H}$ ). Sildenafil treatment reduced the influx of MPO-positive cells by $67.3 \%$ ( $p<0.001$; Figure 4, panels $\mathrm{F}$ and $\mathrm{H}$ ) compared to oxygen-exposed controls.
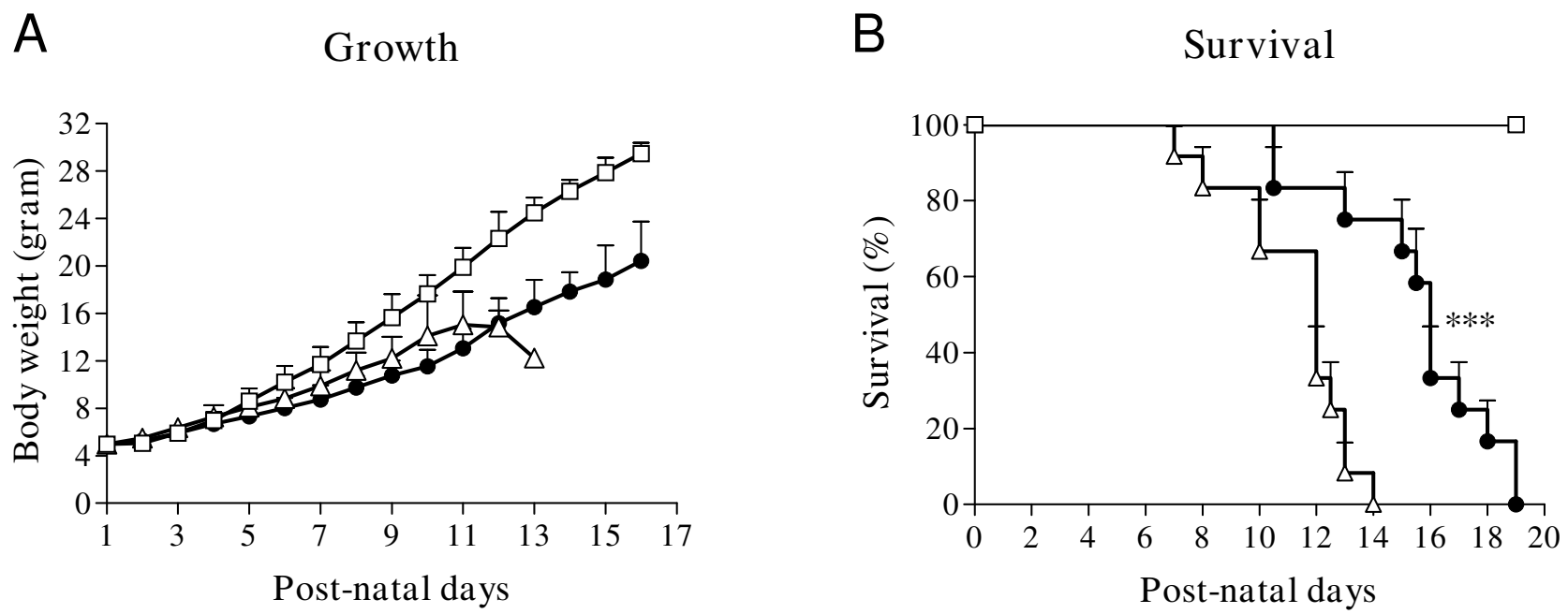

Figure 2

Growth in sildenafil-treated rat pups $\left(100 \mathrm{mg} / \mathrm{kg} / \mathrm{day}\right.$, black circle), age-matched $\mathrm{O}_{2}$-exposed controls (open triangle) and room air exposed controls (open square) during the first 16 days after birth. Data are expressed as mean \pm SEM (panel A). Kaplan-Meier survival curve of sildenafil-treated rat pups (black circle), age-matched $\mathrm{O}_{2}$-exposed controls (open triangle) and room air exposed controls (open square) during the first 19 days after birth (panel B). Data are expressed as percentage \pm SEM of pups surviving at the observed time point. At least 12 pups per experimental group were studied. $* * * p<0.00$ I for sildenafil-treated pups versus age-matched $\mathrm{O}_{2}$-exposed controls. 

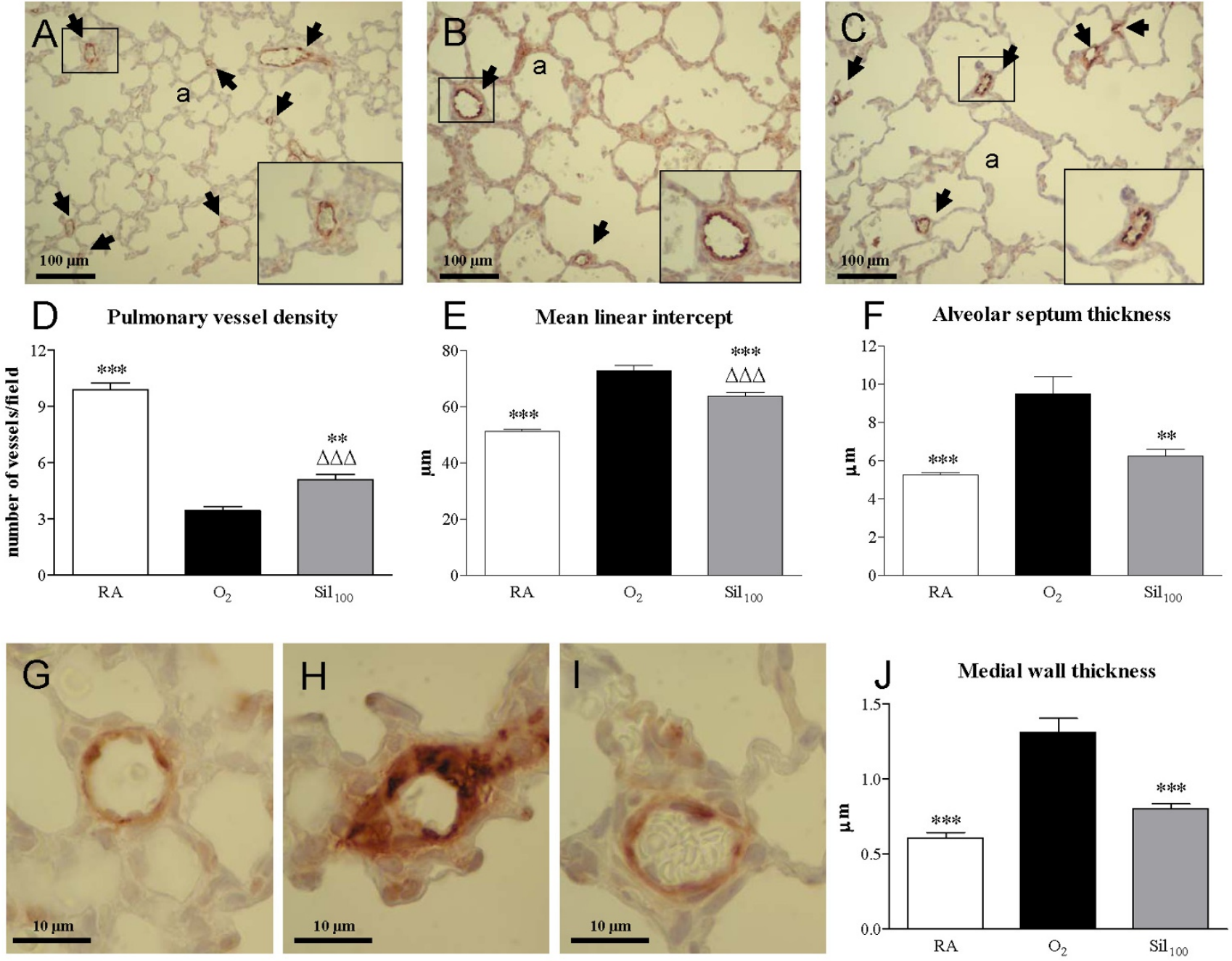

\section{Figure 3}

Paraffin lung sections stained with polyclonal anti-vWF antibody (panels A-C) to visualize the endothelium of pulmonary vessels for the quantification of pulmonary vessel density (panel D) of room-air (RA, panel $A)$ and $\mathrm{O}_{2}$-exposed controls (panel B), and age-matched pups treated with sildenafil ( $100 \mathrm{mg} / \mathrm{kg} / \mathrm{day}$ ) under hyperoxia (panel C) at 10 days of age. Pictures were taken at a $200 \times$ magnification. Arrows in panels A-C indicate vWF-positive blood vessels. Quantification of pulmonary vessel density (panel D), mean linear intercept (panel E), alveolar septum thickness (panel F) and medial wall thickness (panel J) in room air-exposed littermates (white bars), $\mathrm{O}_{2}$-exposed control pups (black bars) and $100 \mathrm{mg} / \mathrm{kg} /$ day sildenafil-treated pups (Sil ${ }_{100}$, gray bars). Paraffin lung sections stained with monoclonal anti-ASMA antibody for the visualization of medial wall thickness in pulmonary arterioles (panels $G-I)$ of room-air (RA, panel $G$ ) and $\mathrm{O}_{2}$-exposed controls (panel $\mathrm{H}$ ), and age-matched pups treated with sildenafil $(100 \mathrm{mg} / \mathrm{kg} /$ day) under hyperoxia (panel I) at I0 days of age. Pictures were taken at a $1000 \times$ magnification. The enlargements shown in the lower right parts of panels $A, B$ and $C$ are indicated in the boxed areas. Values are expressed as mean \pm SEM in at least 6 different rat pups per group. $a=$ alveolus $* * p<0.01$ and $*_{* * *} p<0.001$ versus age-matched $\mathrm{O}_{2}$-exposed controls. ${ }^{\Delta \Delta \Delta} p<0.001$ versus room air-exposed controls.

\section{Protein in bronchoalveolar lavage fluid}

Total protein concentration in bronchoalveolar lavage fluid (BALF) was measured to establish the inhibitory effect of sildenafil on pulmonary edema by capillary-alveolar leakage (Figure 4I). Protein concentration on postnatal day 10 increased 9.4-fold after hyperoxia and had decreased by $52.5 \%$ after treatment with sildenafil $(p<$ 0.05; hyperoxia versus sildenafil).

$m R N A$ expression in lung tissue

Ten days of oxygen exposure resulted in an increase in mRNA expression of the pro-inflammatory cytokine IL-6 (133-fold; $p<0.001$, Figure 5A), the procoagulant factor 

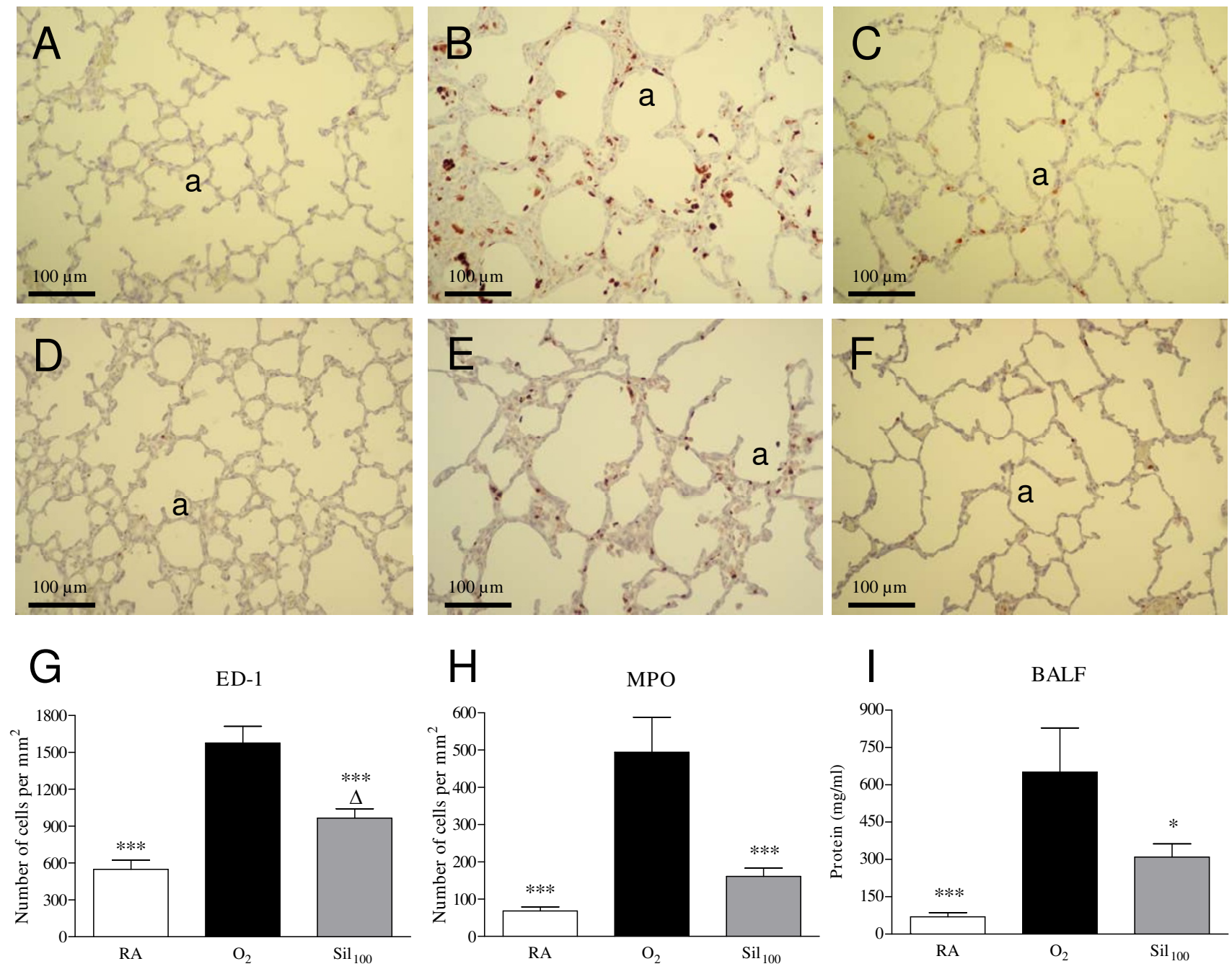

Figure 4

Paraffin lung sections stained with monoclonal anti-ED-I antibody (panels A-C) or polyclonal anti-MPO antibody (panels D-F) of room-air (RA, panels $A$ and $D$ ) and $O_{2}$-exposed controls (panels $B$ and $E$ ), and agematched pups treated with sildenafil $(100 \mathrm{mg} / \mathrm{kg} / \mathrm{day})$ under hyperoxia (panels $C$ and $\mathrm{F})$ at 10 days of age. Pictures were taken at a $200 \times$ magnification. Quantification of ED-I-positive monocytes and macrophages (panel G), MPO-positive neutrophilic granulocytes (panel $\mathrm{H}$ ) and total protein concentration in bronchoalveolar lavage fluid (BALF; panel I) in room air-exposed littermates (white bars), $\mathrm{O}_{2}$-exposed control pups (black bars) and $100 \mathrm{mg} / \mathrm{kg} /$ day sildenafil-treated $\mathrm{O}_{2}$-exposed pups (Sil ${ }_{100}$, gray bars) for 10 days. Values are expressed as mean \pm SEM in at least 6 different rat pups per group. Note the presence of large numbers of leukocytes, including macrophages and neutrophils in thickened septa and in the enlarged alveolar lumen in panels $B$ and $E$ in hyperoxia-exposed controls, and low numbers of pulmonary inflammatory cells after sildenafil treatment (panels $C$ and $F$ ). $a=$ alveolus. ${ }^{*} p<0.05$ and ${ }^{* * *} p<<0.00$ I versus age-matched $\mathrm{O}_{2}$-exposed controls. $\Delta p<0.05$ and versus room air-exposed controls.

tissue factor (TF, 3.0-fold; $p<0.001$, Figure 5B), the fibrinolytic factor plasminogen activator inhibitor-1 (PAI-1, 50-fold; $p<0.001$, Figure 5C) and the growth factor amphiregulin (5.2-fold; $p<0.001$, Figure 5D), and a decrease in the expression of vascular endothelial growth factor receptor-2 (VEGFR2, 3.5-fold; $p<0.001$, Figure 5E) and fibroblast growth factor receptor-4 (FGFR4, 9.0-fold; $p<0.001$, Figure 5F) in lungs of oxygen-exposed compared to room air-exposed pups. Treatment with $100 \mathrm{mg} /$ $\mathrm{kg} /$ day sildenafil resulted in a reduction in PAI-1 (by $26.8 \% ; p<0.05$, Figure 5C) and amphiregulin (by 33.3\%; $p<0.05$, Figure 5D) mRNA expression, whereas sildenafil treatment showed only a tendency towards lower IL- 6 and TF mRNA expression compared to oxygen-exposed con- 

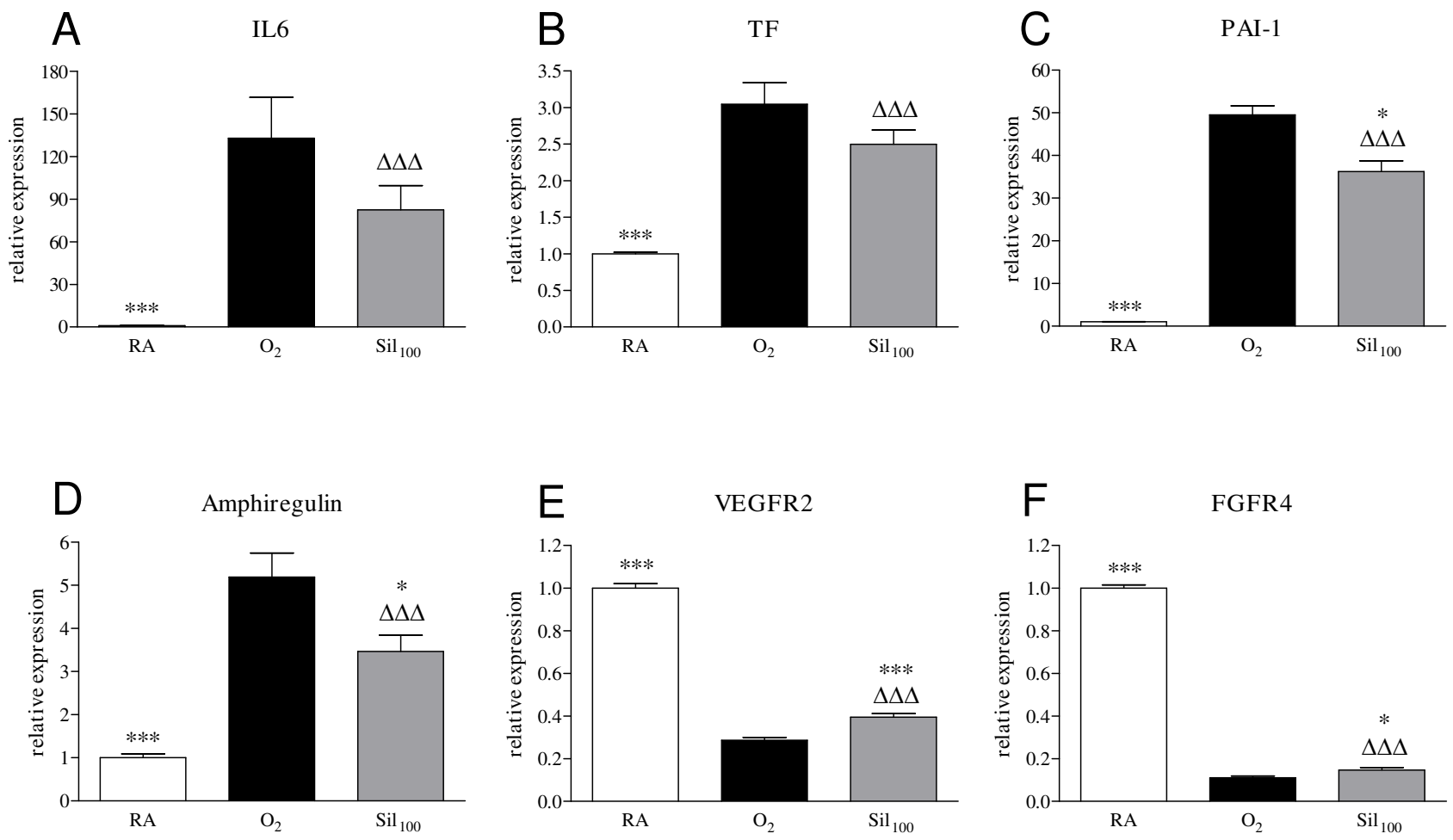

Figure 5

Relative mRNA expression, determined with RT-PCR, of genes related to inflammation; interleukin-6 (IL-6; panel A), coagulation; tissue factor (TF; panel B), fibrinolysis; plasminogen activator inhibitor-I (PAI-I; panel C) and alveolar growth; amphiregulin (panel D), vascular endothelial growth factor receptor-2 (VEGFR2; panel E) and fibroblast growth factor receptor-4 (FGFR4; panel F) in room air-exposed controls (RA, white bars), age-matched $O_{2}$-exposed controls $\left(\mathrm{O}_{2}\right.$, black bars) and sildenafil-treated rat pups ( $100 \mathrm{mg} / \mathrm{kg} / \mathrm{day}$ [Sil $\left.{ }_{100}\right]$, gray bars) on day 10 . Data are expressed as mean \pm SEM of 10 rat pups. $* p<0.05$ and $* * * p<0.001$ versus agematched $\mathrm{O}_{2}$-exposed controls. ${ }^{\Delta \Delta \Delta} p<0.001$ versus room air-exposed controls.

trols. In lung tissue of sildenafil-treated rat pups expression of VEGFR2 and FGFR4 mRNA was increased by $37.5 \%(p<0.001)$ and by $32.6 \%(p<0.05)$, respectively, compared to oxygen-exposed pups (Figure 5, panels E and F).

\section{Right ventricular hypertrophy}

Exposure to hyperoxia for 10 days resulted in RVH as demonstrated by a 1.4 -fold increase in the weight ratio $\mathrm{RV} /(\mathrm{LV}+\mathrm{IVS})$ compared to room air controls $(p<0.001$;
Table 2; Figure 6A). Treatment with sildenafil resulted in a significant regression of RVH (Figure 6A) and a decrease of the RV wall thickness by $26.8 \%$ compared to the oxygen-exposed controls ( $p<0.05$, Figure 6B). Extracellular expression of tenascin-C, a marker of myocardial overload, was visible in the RV only after exposure to hyperoxia. Tenascin-C expression was absent in room air exposed controls, as well as after treatment with sildenafil in experimental BPD (Figure 6, panels C-E).

Table 2: Cardiac characteristics

\begin{tabular}{llll}
\hline & RA & $O_{2}$ & Sil $_{100}$ \\
\hline RV free wall thickness $(\mu \mathrm{m})$ & $240 \pm 6$ & $310 \pm 34$ & $197 \pm 1 I^{*}$ \\
LV free wall thickness $(\mu \mathrm{m})$ & $575 \pm 13$ & $568 \pm 39$ & $515 \pm 34$ \\
IVS thickness $(\mu \mathrm{m})$ & $563 \pm 67$ & $568 \pm 102$ & $454 \pm 62$ \\
RV/(LV+IVS) & $0.302 \pm 0.02^{* * * *}$ & $0.412 \pm 0.02$ & $0.343 \pm 0.01 *$ \\
\hline
\end{tabular}

*** $p<0.001$ and $* p<0.05$ versus age-matched $\mathrm{O}_{2}$ exposed controls. 

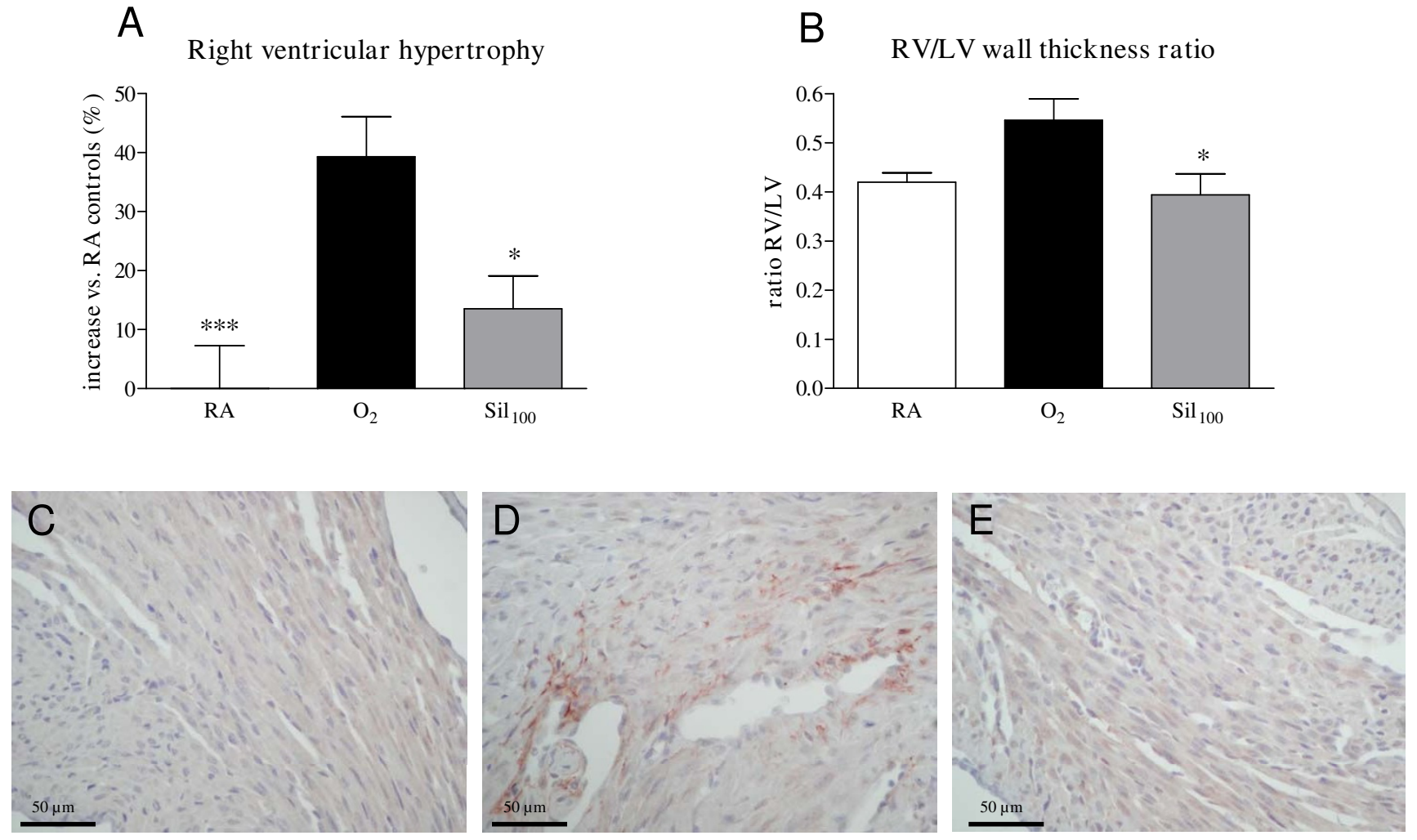

\section{Figure 6}

Right ventricular hypertrophy is depicted as the increase in the ratio RVI(LV+IVS) compared to the room air control (panel A) and ventricular wall thickness, indicated as the RV/LV ratio (panel B) in room air-exposed controls (RA, white bars), age-matched $\mathrm{O}_{2}$-exposed controls $\left(\mathrm{O}_{2}\right.$, black bars) and sildenafil-treated rat pups ( $100 \mathrm{mg} / \mathrm{kg} /$ day [Sil ${ }_{100}$ ], gray bars) under hyperoxia on day I O. Cardiac characteristics are presented in table 2. Paraffin sections of the right ventricular wall stained with polyclonal tenascin $\mathrm{C}$ (panels $\mathrm{C}-\mathrm{E}$ ) of room-air (RA, panel $\mathrm{C})$ and $\mathrm{O}_{2}$-exposed controls (panel D), and age-matched pups treated with sildenafil (I00 mg/kg/day) under hyperoxia (panel E) at I0 days of age. Note the extravascular expression of tenascin $C$ in the right ventricle in oxygen-exposed pups (panel D) and the absence of staining after treatment with sildenafil (panel E) and in room air controls (panel C). Pictures were taken at a $400 \times$ magnification.

mRNA expression in the heart

Increased right ventricular mRNA expression was observed for the natriuretic peptides ANP (2.5-fold; $p<$ 0.01 , Figure 7A) and BNP (3.3-fold; $p<0.001$, Figure 7B), whereas expression was decreased for CNP (5.5-fold; $p<$ 0.001 , Figure 7C) and for the natriuretic peptide receptors (NPR) -A (1.7-fold; $p<0.001$, Figure 7D) and NPR-B (2.1fold; $p<0.001$, Figure 7E) after exposure to hyperoxia for 10 days compared to room air controls. Treatment with sildenafil decreased the expression of BNP (by 36.3\%; $p<$ 0.01 ) and increased the expression of CNP (by 267\%; $p<$ 0.001 ), NPR-A (by 24.7\%; $p<0.05$ ), NPR-B (by 35.7\%; $p$ $<0.05$ ) and NPR-C (by 39.2\%; $p<0.05$, Figure 7F) compared to oxygen-exposed controls.

\section{Neonatal lung injury-recovery model \\ Lung histology}

Continuous neonatal exposure to hyperoxia for 9 days resulted in a 2.5-fold reduction in blood vessel density ( $p$ $<0.001$; Figure 8 panels B and G) and enlarged alveoli (Figure $8 \mathrm{~B})$, demonstrated by an increased MLI $(p<0.001$, Figure $8 \mathrm{H}$ ) and a 3.1-fold increase in medial wall thickness $(p<0.001$; Figure 9, panels B and $G$ ) compared to room air controls. Sildenafil treatment during the last 3 days of the injurous hyperoxic period decreased medial wall thickness by $27.4 \%\left(p<0.05\right.$ vs $\mathrm{O}_{2}$; Figure 9, panels C and G), but did not affect alveolar enlargement and blood vessel density (Figure 8, panels C, G and H). A recovery period of 9 days in room air after hyperoxiainduced lung injury (Figure $8 \mathrm{E}$ ) reduced MLI (Figure $8 \mathrm{H}$ ) and increased blood vessel density (Figure 8G), but alveoli continued to be enlarged (Figure 8E). Treatment with 

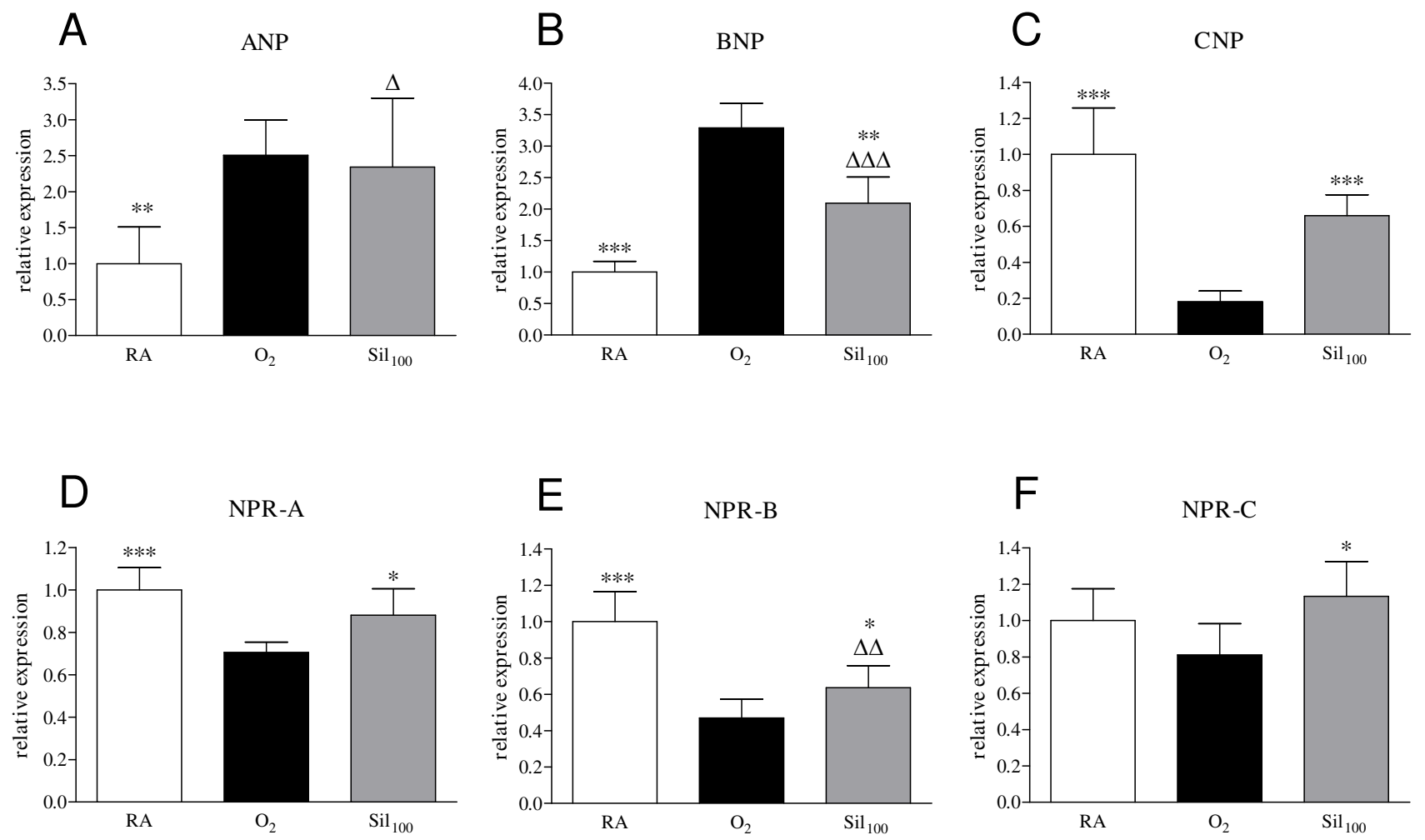

Figure 7

mRNA expression in the right ventricle, relative to the expression in the left ventricle and interventricular septum, determined with RT-PCR, of atrial natriuretic peptide (ANP; panel A), brain natriuretic peptide (BNP; panel B), c-type natriuretic peptide (CNP; panel C), natriuretic peptide receptor (NPR) -A (panel D), NPR-B (panel E) and NPR-C (panel F) in room air-exposed controls (RA, white bars), age-matched $\mathrm{O}_{2}-$ exposed controls $\left(\mathrm{O}_{2}\right.$, black bars) and sildenafil-treated rat pups ( $100 \mathrm{mg} / \mathrm{kg} / \mathrm{day}$ [Sil $\left.{ }_{100}\right]$, gray bars) under hyperoxia on day 10 . Data are expressed as mean \pm SEM of 10 rat pups. $*_{p}<0.05$, $* * p<0.01$ and $* * * p<0.001$ versus agematched $\mathrm{O}_{2}$-exposed controls. ${ }^{\Delta} p<0.05,{ }^{\Delta} p p<0.0 \mathrm{I}$ and ${ }^{\Delta \Delta \Delta} p<0.00 \mathrm{I}$ versus room air-exposed controls.

sildenafil restored blood vessel density $\left(p<0.05\right.$ vs $\mathrm{O}_{2}$; Figure 8 , panels F and G) and reduced MLI by $11.8 \%(p<$ $0.001 \mathrm{vs}_{2}$, Figure $8 \mathrm{H}$ ) compared to non-treated experimental BPD pups. However, medial wall thickness was only reduced in sildenafil-treated pups by $47 \%(p<0.001$; Figure 9, panels D-G) after a 9-day recovery period in room air.

Nine days of hyperoxic lung injury resulted in a 1.4-fold increase in the ratio RV/LV wall thickness, which was significantly reduced after sildenafil treatment for 3 days $(42.2 \% ; p<0.001$, Figure $9 N)$. A recovery period of 9 days did not reduce $\mathrm{RVH}$ in the non-treated experimental BPD pups, but the RV/LV wall thickness ratio was completely restored after sildenafil treatment.

\section{Discussion}

Prophylactic sildenafil therapy prolonged survival, improved lung histopathology, reduced $\mathrm{RVH}$, and increased lung cGMP levels in neonatal rat pups exposed to continuous and prolonged hyperoxia, a suitable in vivo model for experimental BPD [8], by inhibiting inflammation, reducing capillary-alveolar protein leakage, alveolar septum thickness, and alveolar enlargement and by attenuating alveolar fibrin deposition in neonatal rat pups exposed to prolonged hyperoxia. Inhibition of lung inflammation was demonstrated by a reduction in the influx of inflammatory cells, including macrophages and neutrophilic granulocytes. Sildenafil therapy started after the initiation of hyperoxia-induced lung injury improved alveolarization and angiogenesis by attenuating alveolar enlargement and arteriolar medial wall thickness, and restoring pulmonary bloodvessel density and RVH in a lung injury-recovery model, demonstrating its therapeutic potential for treatment of BPD in the neonatal intensive care unit. 


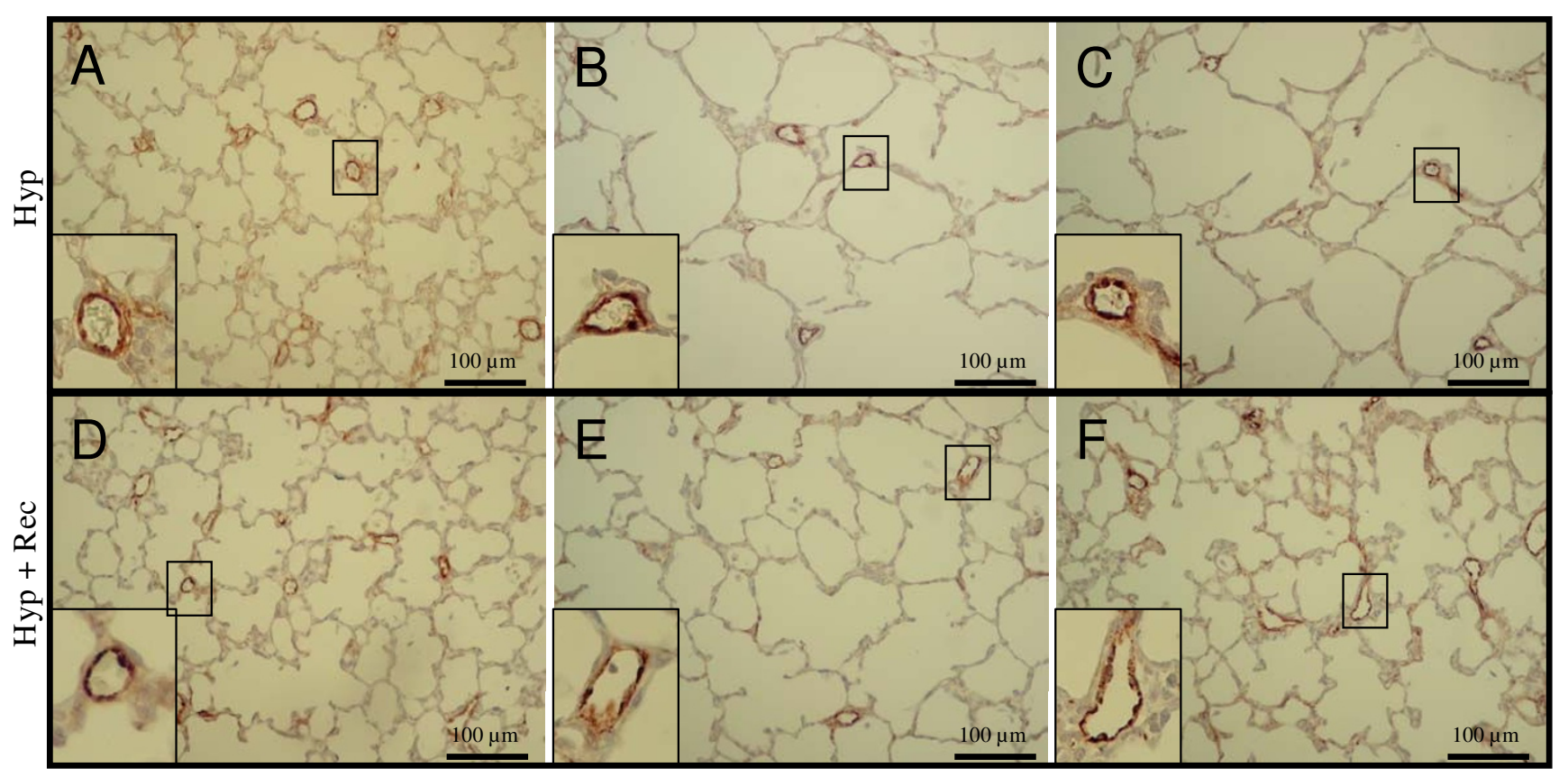

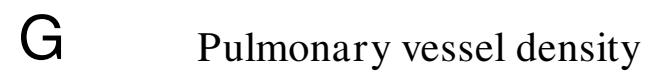

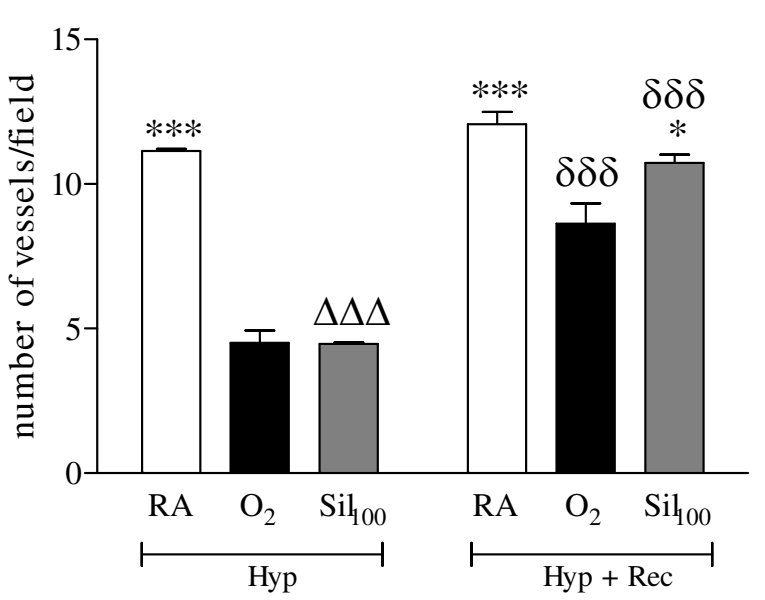

$\mathrm{H}$

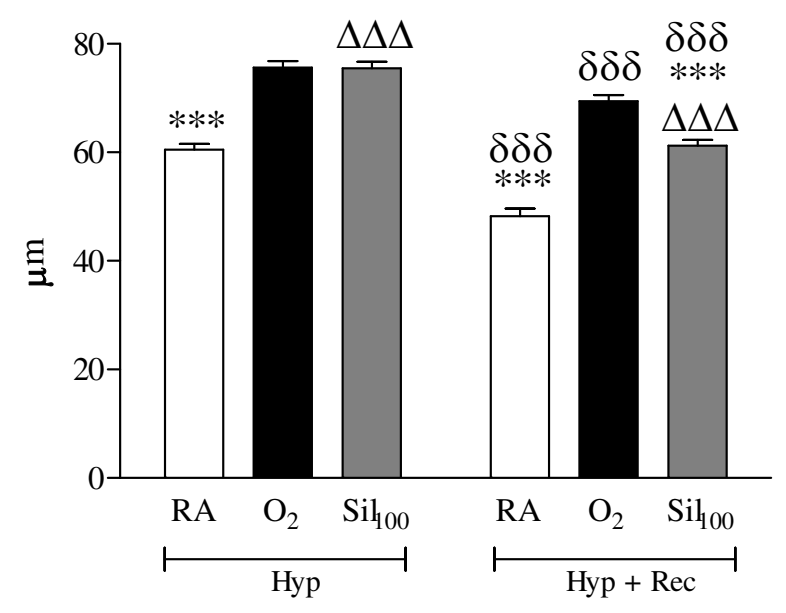

Figure 8

Paraffin lung sections stained with polyclonal anti-vWF antibody (panels A-F) after hyperoxic injury for 9 days (panels A-C) and subsequent recovery in room air for 9 days (panels D-F) of room-air (RA, panel A), $\mathrm{O}_{2-}$ exposed (panel B) and age-matched pups treated with sildenafil $(100 \mathrm{mg} / \mathrm{kg} /$ day) under hyperoxia (panel C), and of RA (panel D), $\mathrm{O}_{2}$-exposed (panel E) and age-matched $\mathrm{O}_{2}$-exposed pups treated with sildenafil ( $100 \mathrm{mg} /$ kg/day, panel F) after recovery. Pictures were taken at a 200x magnification. Quantification of pulmonary vessel density (panel $G$ ) and mean linear intercept (panel $H$ ) after hyperoxic lung injury for 9 days (Hyp in panels $G$ and $H$ ) and after recovery in room air for 9 days (Hyp + Rec in panels $\mathrm{G}$ and $\mathrm{H}$ ) in room air-exposed (white bars), $\mathrm{O}_{2}$-exposed (black bars) and $\mathrm{O}_{2}$ exposed pups treated with $100 \mathrm{mg} / \mathrm{kg} /$ day sildenafil (Sil ${ }_{100}$, gray bars). The enlargements shown in the lower left parts of panels A-F are indicated in the boxed areas. ${ }^{*} p<0.05$ and $* * * p<0.001$ versus age-matched $\mathrm{O}_{2}$-exposed controls. $\Delta \Delta \Delta_{p}<0.00$ I versus room air-exposed controls. ${ }^{\delta \delta \delta} \mathrm{p}<0.00 \mathrm{I}$ versus own treatment controls in hyperoxia period (hyp). 

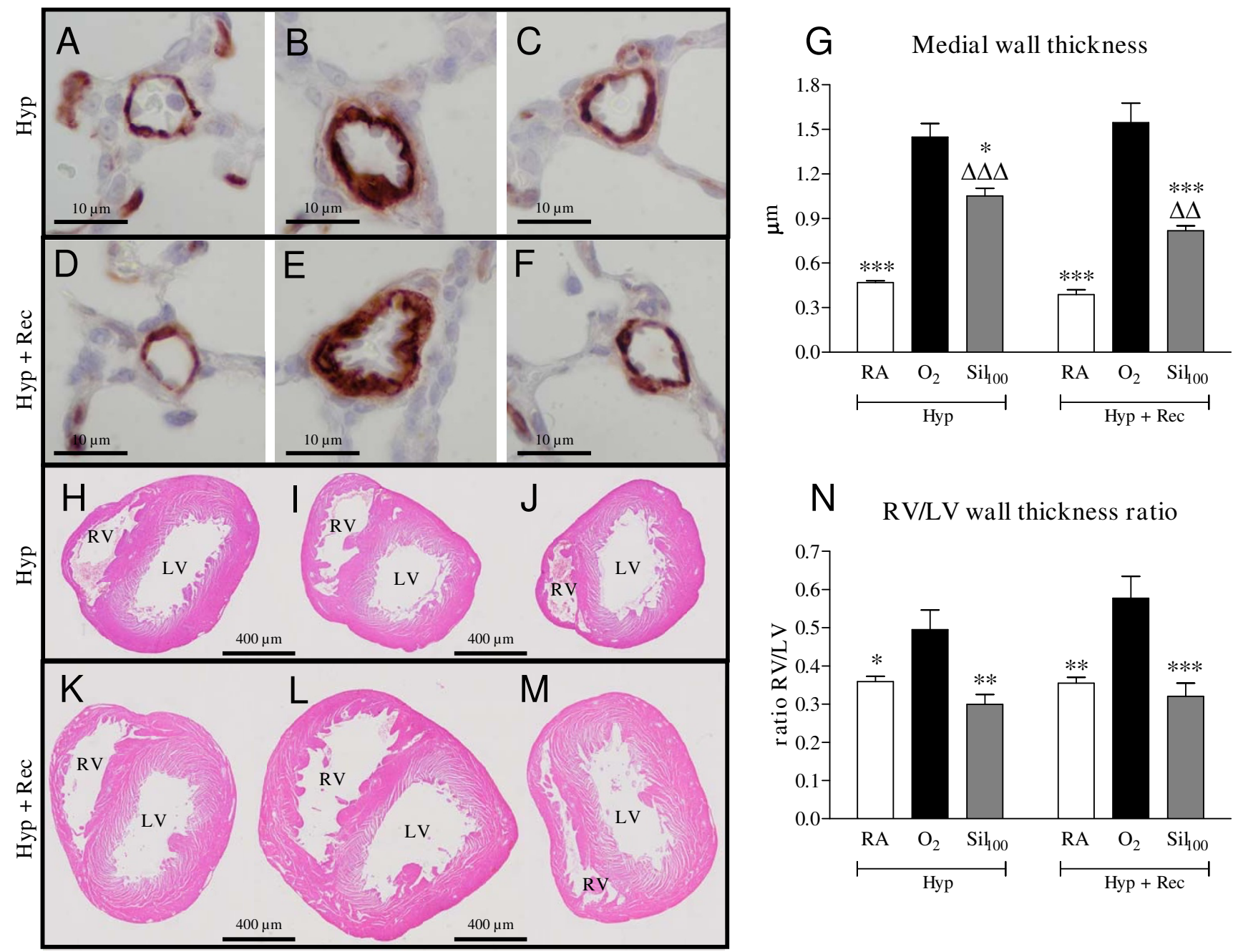

Figure 9

Paraffin lung sections stained with monoclonal anti-ASMA antibody (panels A-F) and paraffin heart sections stained with HE (panels H-M) after hyperoxic injury for 9 days (panels A-C and $\mathrm{H}-\mathrm{J}$ ) and subsequent recovery in room air for 9 days (panels D-F and K-M) of room-air (RA, panels $A$ and $H$ ), $O_{2}$-exposed (panels $B$ and $I$ ) and age-matched pups treated with sildenafil ( $100 \mathrm{mg} / \mathrm{kg} /$ day) under hyperoxia (panels $C$ and $\mathrm{J})$, and of RA (panels $\mathrm{D}$ and $\mathrm{K}$ ), $\mathrm{O}_{2}$-exposed (panels $\mathrm{E}$ and $\mathrm{L}$ ) and age-matched $\mathrm{O}_{2}$-exposed pups treated with sildenafil ( $100 \mathrm{mg} / \mathrm{kg} /$

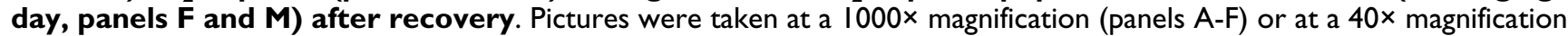
(panels H-M). Quantification of pulmonary arteriolar medial wall thickness (panel G) and right ventricular hypertrophy (RV/LV wall thickness ratio, panel $\mathrm{N}$ ) after hyperoxic lung injury for 9 days (Hyp in panels $\mathrm{G}$ and $\mathrm{N}$ ) and after recovery in room air for 9 days (Hyp + Rec in panels $\mathrm{G}$ and $\mathrm{N}$ ) in room air-exposed (white bars), $\mathrm{O}_{2}$-exposed (black bars) and $\mathrm{O}_{2}$-exposed pups treated with $100 \mathrm{mg} / \mathrm{kg} /$ day sildenafil (Sil 100 , gray bars). LV = left ventricle and $\mathrm{RV}=$ right ventricle. ${ }^{*} p<0.05, *_{p}{ }_{p}<0.0 \mathrm{I}$ and $*^{* * *} p<$ $0.00 \mathrm{I}$ versus age-matched $\mathrm{O}_{2}$-exposed controls. $\Delta \Delta p<0.0 \mathrm{I}$ and $\Delta \Delta \Delta_{p}<0.00 \mathrm{I}$ versus room air-exposed controls.

In vitro studies of lipopolysaccharide (LPS) mediated cytokine production in alveolar epithelial cells and in vivo studies on the influx of macrophages and neutrophils in a rat model of airway hyperreactivity have demonstrated the anti-inflammatory properties of PDE5 inhibition on pulmonary inflammatory processes $[15,24]$. Increased neo-vascularization in chicken chorioallantoic membranes has shown that sildenafil stimulation angiogenesis
[25]. The improvement of alveolarization after sildenafil treatment in our study confirms, in part, the findings of Ladha et al, who investigated the effects of prophylactic sildenafil treatment in a similar rat model using quantitative histopathological techniques [14]. Lung injury in hyperoxia-exposed pups in this study was more severe as we used a different rat strain (Wistar instead of SpragueDawley rats, which are more resistant against hyperoxic 
lung injury), $100 \%$ instead of $95 \%$ oxygen and differences in the onset of lung injury.

We have previously shown that the specific inhibition of PDE4 with rolipram or piclamilast reduces alveolar fibrin deposition, inflammation and vascular alveolar leakage, and prolongs survival in rats with neonatal hyperoxic lung injury [6]. PDE4 inhibitors can exert their protective effect in inflammatory lung diseases by increasing intracellular cAMP levels [26]. PDEs belong to an enzyme family with 11 different members, designated PDE1-11, which exert their biological function by inactivating the intracellular messengers cAMP and/or cGMP by hydrolysis [26-28]. The beneficial effects of PDE5 inhibition by sildenafil on hyperoxia-induced lung injury may, at least in part, be due to higher intracellular cGMP levels as demonstrated by increased cGMP levels in lung homogenates (this study). In contrast to previous studies in which hyperoxic lung injury resulted in either increased $[14,29]$ or decreased cGMP levels [30] we did not observe differences in cGMP levels in experimental BPD. This may be explained by differences in tissue source: plasma [14] versus lung tissue (this study) and the duration of the injurious hyperoxic response [30].

We have recently demonstrated that inhaled NO therapy improves lung pathology, reduces fibrin deposition and pulmonary inflammation, and prolongs survival in an animal model of BPD [7]. NO plays an important role in regulating pulmonary vascular tone and alveolar capillary development and in reducing inflammation in the developing lung $[7,31,32]$. Inhaled NO can exert its biological effects via the S-nitrosylation or via the NO-cGMP pathway $[31,33,34]$. The similarity of beneficial effects by inhaled NO and sildenafil treatment in experimental BPD suggests that the NO-cGMP pathway plays an important role in the pathogenesis of experimental BPD. Sildenafiltreated pups survived longer than pups treated with inhaled NO, but the effects of sildenafil treatment on pulmonary fibrin deposition and inflammation were less pronounced than the effects of inhaled NO. Intervention studies in hyperoxic lung injury with inhaled NO and (selective) PDE inhibitors have demonstrated less inflammation, but, incomplete restoration of lung development resulting in persistent enlarged alveoli $[6,7,14,33]$. Alveolar enlargement was accompanied by a downregulation of FGFR-4 which was partially restored after treatment with sildenafil. This confirms the observation that lungs of FGFR-3(-/-)/FGFR-4(-/-) mice are normal at birth, but have a complete block in alveogenesis and do not form secondary septa, demonstrating their cooperative function to promote the formation of alveoli [35].

NO stimulates the formation of cGMP in the endothelium and smooth muscle cells $[14,36]$, whereas sildenafil pro- tects CGMP from degradation by inhibiting PDE5 activity, but both modalities result in increased intracellular cGMP levels in these cells. Enhanced cGMP levels reduce pulmonary vascular resistance by relaxation of vascular smooth muscle cells and induce redistribution of pulmonary blood flow to ventilated lung regions, thereby preventing further lung injury $[11,17,37]$. Sildenafil and inhaled NO have both been used in term newborns with severe persistent pulmonary hypertension $[16,17,37,38]$, a late complication of BPD. Early use of inhaled NO may improve the chances of survival without BPD in ventilated preterm infants [39], but data on sildenafil use in this group are not available. In addition, enhanced cGMP levels in endothelial cells improves angiogenesis and alveolarization via the vascular endothelial growth factor (VEGF)-NO-cGMP pathway [40,41]. Recombinant human VEGF treatment enhances alveolarization and vessel growth and improves lung structure in hyperoxiainduced neonatal lung injury $[42,43]$. On the contrary, VEGF blockade in newborn rats impairs alveolarization and vessel growth [44]. In experimental BPD in newborn rats alveolar enlargement and loss of lung capillaries are associated with decreased expression of lung VEGF and VEGF receptor-2 (VEGFR2) [44], whereas sildenafil improves alveolarization and angiogenesis [14], and reduces pulmonary fibrin deposition, inflammation and vascular alveolar leakage, resulting in prolonged survival in the present study. In lung injury-recovery models of experimental BPD alveoli are still enlarged after recovery in non-treated pups $[42,44]$, but alveolarization and angiogenesis are almost completely restored after treatment with pro-angiogenic factors, such as VEGF $[42,44]$ and sildenafil (this study). These results strongly suggest that sildenafil treatment of preterm infants may reverse the arrest in lung development which is typical for those developing BPD.

Sildenafil treatment improved hyperoxia-induced RVH in experimental BPD (this study and [14]), reduced extracellular tenascin- $\mathrm{C}$ expression in the $\mathrm{RV}$, a marker that is upregulated under myocardial stress conditions [45,46], and reduced the thickness of the RV. The beneficial effect of sildenafil on the heart can be explained either directly or indirectly by a reduction of pulmonary hypertension resulting in reduced $\mathrm{RVH}$. This is supported by a sildenafil-induced reduction in pulmonary arteriolar wall thickness (this study) and by similar beneficial effects of PDE5inhibitors in experimental models of lung disease, including monocrotaline-induced pulmonary hypertension and bleomycin-induced pulmonary fibrosis [47-49]. A direct beneficial effect of sildenafil is supported by an induction of PDE5 in the myocardium of the hypertrophied LV or $\mathrm{RV}$ in patient material and in the RV after monocrotalineinduced RVH in rats [50]. In addition, Nagendran et al. have demonstrated that sildenafil treatment restored the 
upregulated cGMP-PDE activity in RV of rats with monocrotaline-induced pulmonary artery hypertension and increased RV contractility of these rats.

The natriuretic peptides atrial natriuretic peptide (ANP) and brain natriuretic peptide (BNP) are synthesized and released in response to atrial pressure and ventricular overload, respectively, and their plasma concentrations are related to ventricular dysfunction and severity of cardiac pathology $[51,52]$. Occupation of the natriuretic peptide receptor (NPR) -A, activated by ANP, BNP and DNP, and NPR-B, which is specific to CNP, induces cellular responses via activation of particulate guanylate cyclase, in contrast to soluble guanylate cyclase that is activated by $\mathrm{NO}$, thereby elevating the intracellular levels of cGMP $[53,54]$. As markers for RVH we studied the differential expression of ANP, BNP, CNP and the natriuretic peptide receptors NPR-A, NPR-B and NPR-C at the mRNA level. Hyperoxia-induced RVH resulted in reduced expression of the guanylate cyclase-coupled natriuretic peptide receptors NPR-A and NPR-B in cardiomyocytes. Signaling after activation of these receptors by natriuretic peptides is mediated by cGMP [54]. This suggests that the intracellular cGMP concentration in the hypertrophic RV cardiomyocyte is not only lowered by increased PDE5 expression, but may also be reduced due to decreased levels of NPR-A and NPR-B, which can be restored, at least in part, by sildenafil treatment.

\section{Conclusion}

The beneficial effects of sildenafil on alveolarization, lung inflammation and extravascular fibrin deposition, right ventricular hypertrophy and survival in neonatal rats with hyperoxia-induced lung injury emphasise the potential of phosphodiesterase 5 inhibitors as treatment for bronchopulmonary dysplasia in premature infants.

\section{Abbreviations}

ANP: atrial natriuretic peptide; ASMA: alpha smooth muscle actin; BNP: brain natriuretic peptide; BALF: bronchoalveolar lavage fluid; BPD: bronchopulmonary dysplasia; cAMP: cyclic adenosine monophosphate; cGMP: cyclic guanosine monophosphate; CNP: c-type natriuretic peptide; FGFR4: fibroblast growth factor receptor-4; IL: interleukin; IVS: interventricular septum; LV: left ventricle; MLI: mean linear intercept; MPO: myeloperoxidase; NO: nitric oxide; NPR: natriuretic peptide receptor; $\mathrm{O}_{2}$ : oxygen; PAI-1: plasminogen activator inhibitor-1; PDE: phosphodiesterase; RA: room air; RT-PCR: reverse transcriptase polymerase chain reaction; RV: right ventricular free wall; TF: tissue factor; VEGFR2: vascular endothelial growth factor (VEGF) receptor-2; vWF: Von Willebrand Factor.

\section{Competing interests}

The authors declare that they have no competing interests.

\section{Authors' contributions}

YPV, EHL and HB carried out the experimental studies. YPV drafted the manuscript. GTMW, FJW and AL designed the experimental setup and provided intellectual input in the manuscript preparation. GTMW supervised the work.

\section{Acknowledgements}

The authors gratefully acknowledge Professor J.C.M. Meijers and Professor T. van der Poll for providing the 59D8 antibody and Dr. E. de Heer for providing the ED-I antibody.

This study was supported by grant IROI HL092 I 58 from the National Institutes of Health (F. J. Walther).

\section{References}

I. Jobe $A H$, Ikegami $M$ : Mechanisms initiating lung injury in the preterm. Early Hum Dev 1998, 53:81-94.

2. Goodman G, Perkin RM, Anas NG, Sperling DR, Hicks DA, Rowen M: Pulmonary hypertension in infants with bronchopulmonary dysplasia. J Pediatr 1988, I I 2:67-72.

3. Aranda JV, Grondin D, Sasyniuk BI: Pharmacologic considerations in the therapy of neonatal apnea. Pediatr Clin North Am 1981, 28: I13-133.

4. Harris MC, Baumgart S, Rooklin AR, Fox WW: Successful extubation of infants with respiratory distress syndrome using aminophylline. J Pediatr 1983, 103:303-305.

5. ter Horst SA, Wagenaar GT, de Boer E, van Gastelen MA, Meijers JC, Biemond BJ, et al.: Pentoxifylline reduces fibrin deposition and prolongs survival in neonatal hyperoxic lung injury. J Appl Physiol 2004, 97:2014-2019.

6. de Visser YP, Walther FJ, Laghmani EH, van Wijngaarden S, Nieuwland K, Wagenaar GT: Phosphodiesterase 4 inhibition attenuates pulmonary inflammation in neonatal lung injury. Eur Respir J 2007, 3 I:633-644.

7. ter Horst SA, Walther FJ, Poorthuis BJ, Hiemstra PS, Wagenaar GT: Inhaled nitric oxide attenuates pulmonary inflammation and fibrin deposition and prolongs survival in neonatal hyperoxic lung injury. Am J Physiol Lung Cell Mol Physiol 2007, 293:L35-L44.

8. Wagenaar GT, ter Horst SA, van Gastelen MA, Leijser LM, Mauad T, Velden PA van der, et al.: Gene expression profile and histopathology of experimental bronchopulmonary dysplasia induced by prolonged oxidative stress. Free Radic Biol Med 2004, 36:782-801.

9. Essayan DM: Cyclic nucleotide phosphodiesterases. J Allergy Clin Immunol 200I, 108:67I-680.

10. Torphy T]: Phosphodiesterase isozymes: molecular targets for novel antiasthma agents. Am J Respir Crit Care Med 1998, I 57:35I-370.

II. Hemnes AR, Champion HC: Sildenafil, a PDE5 inhibitor, in the treatment of pulmonary hypertension. Expert Rev Cardiovasc Ther 2006, 4:293-300.

12. Liu H, Liu ZY, Guan Q: Oral sildenafil prevents and reverses the development of pulmonary hypertension in monocrotalinetreated rats. Interact Cardiovasc Thorac Surg 2007, 6:608-6I3.

13. Hemnes AR, Zaiman A, Champion HC: PDE5A inhibition attenuates bleomycin-induced pulmonary fibrosis and pulmonary hypertension through inhibition of ROS Generation and RhoA/Rho kinase Activation. Am J Physiol Lung Cell Mol Physiol 2007, 294(I):L24-33

14. Ladha F, Bonnet S, Eaton F, Hashimoto K, Korbutt G, Thebaud B: Sildenafil improves alveolar growth and pulmonary hypertension in hyperoxia-induced lung injury. Am J Respir Crit Care Med 2005, I 72:750-756.

15. Toward TJ, Smith N, Broadley KJ: Effect of phosphodiesterase-5 inhibitor, sildenafil (Viagra), in animal models of airways disease. Am J Respir Crit Care Med 2004, I 69:227-234.

16. Baquero H, Soliz A, Neira F, Venegas ME, Sola A: Oral sildenafil in infants with persistent pulmonary hypertension of the newborn: a pilot randomized blinded study. Pediatrics 2006, I | 7:1077-1083

17. Juliana AE, Abbad FC: Severe persistent pulmonary hypertension of the newborn in a setting where limited resources 
exclude the use of inhaled nitric oxide: successful treatment with sildenafil. Eur J Pediatr 2005, 164:626-629.

18. Boolell M, Allen MJ, Ballard SA, Gepi-Attee S, Muirhead GJ, Naylor AM, et al.: Sildenafil: an orally active type 5 cyclic GMP-specific phosphodiesterase inhibitor for the treatment of penile erectile dysfunction. Int J Impot Res 1996, 8:47-52.

19. Dijkstra CD, Dopp EA, Joling P, Kraal G: The heterogeneity of mononuclear phagocytes in lymphoid organs: distinct macrophage subpopulations in the rat recognized by monoclonal antibodies EDI, ED2 and ED3. Immunology 1985, 54:589-599.

20. Liao L, Ning Q, Li Y, Wang W, Wang A, Wei W, et al.: CXCR2 blockade reduces radical formation in hyperoxia-exposed newborn rat lung. Pediatr Res 2006, 60:299-303.

21. Hessel MHM, Steendijk P, den Adel B, Schutte Cl, Laarse A van der: Pressure Overload-Induced Right Ventricular Dilatation is Associated with Re-Expression of Myocardial Tenascin-C and Increased Plasma Levels of Tenascin-C. Circulation 2006, I I 4(II): I33.

22. Hui KY, Haber E, Matsueda GR: Monoclonal antibodies to a synthetic fibrin-like peptide bind to human fibrin but not fibrinogen. Science 1983, 222: I 129-I I 32.

23. Pfaff MW: A new mathematical model for relative quantification in real-time RT-PCR. Nucleic Acids Res 200I, 29(9):e45.

24. Haddad JJ, Land SC, Tarnow-Mordi WO, Zembala M, Kowalczyk D, Lauterbach R: Immunopharmacological potential of selective phosphodiesterase inhibition. I. Differential regulation of lipopolysaccharide-mediated proinflammatory cytokine (interleukin-6 and tumor necrosis factor-alpha) biosynthesis in alveolar epithelial cells. J Pharmacol Exp Ther 2002, 300:559-566.

25. Pyriochou A, Zhou Z, Koika V, Petrou C, Cordopatis P, Sessa WC, et al:: The phosphodiesterase 5 inhibitor sildenafil stimulates angiogenesis through a protein kinase G/MAPK pathway. J Cell Physiol 2007, 2 I I: 197-204.

26. Houslay MD, Schafer P, Zhang KY: Keynote review: phosphodiesterase-4 as a therapeutic target. Drug Discov Today 2005, 10:1503-1519.

27. Conti M, Richter W, Mehats C, Livera G, Park JY, Jin C: Cyclic AMPspecific PDE4 phosphodiesterases as critical components of cyclic AMP signaling. J Biol Chem 2003, 278:5493-5496.

28. Lugnier C: Cyclic nucleotide phosphodiesterase (PDE) superfamily: a new target for the development of specific therapeutic agents. Pharmacol Ther 2006, 109:366-398.

29. Potter CF, Kuo NT, Farver CF, McMahon JT, Chang CH, Agani FH, et al.: Effects of hyperoxia on nitric oxide synthase expression, nitric oxide activity, and lung injury in rat pups. Pediatr Res 1999, 45:8-13.

30. Sopi RB, Haxhiu MA, Martin RJ, Dreshaj IA, Kamath S, Zaidi SI: Disruption of NO-cGMP signaling by neonatal hyperoxia impairs relaxation of lung parenchyma. Am J Physiol Lung Cell Mol Physiol 2007, 293:LI029-LI036.

31. Lin YJ, Markham NE, Balasubramaniam V, Tang JR, Maxey A, Kinsella $J P$, et al.: Inhaled nitric oxide enhances distal lung growth after exposure to hyperoxia in neonatal rats. Pediatr Res 2005, 58:22-29.

32. McCurnin DC, Pierce RA, Chang LY, Gibson LL, Osborne-Lawrence $S$, Yoder BA, et al.: Inhaled NO improves early pulmonary function and modifies lung growth and elastin deposition in a baboon model of neonatal chronic lung disease. Am J Physiol Lung Cell Mol Physiol 2005, 288:L450-L459.

33. Auten RL, Mason SN, Whorton MH, Lampe WR, Foster WM, Goldberg RN, et al: Inhaled Ethyl Nitrite Prevents Hyperoxiaimpaired Postnatal Alveolar Development in Newborn Rats. Am J Respir Crit Care Med 2007, I 76:29I-299.

34. Gaston B, Singel D, Doctor A, Stamler JS: S-nitrosothiol signaling in respiratory biology. Am J Respir Crit Care Med 2006, 173:1186-1193.

35. Weinstein $M, X u X$, Ohyama K, Deng CX: FGFR-3 and FGFR-4 function cooperatively to direct alveogenesis in the murine lung. Development 1998, 125:3615-3623.

36. Humbert M, Sitbon O, Simonneau G: Treatment of pulmonary arterial hypertension. N Engl J Med 2004, 35 I: | 425 - 1436.

37. Leibovitch L, Matok I, Paret G: Therapeutic applications of sildenafil citrate in the management of paediatric pulmonary hypertension. Drugs 2007, 67:57-73.
38. Abman $\mathrm{SH}$ : Recent advances in the pathogenesis and treatment of persistent pulmonary hypertension of the newborn. Neonatology 2007, 91 1:283-290.

39. Barrington KJ, Finer NN: Inhaled nitric oxide for preterm infants: a systematic review. Pediatrics 2007, 120:1088-1099.

40. Hoeben A, Landuyt B, Highley MS, Wildiers H, Van Oosterom AT, De Bruijn EA: Vascular endothelial growth factor and angiogenesis. Pharmacol Rev 2004, 56:549-580.

4I. Voelkel NF, Vandivier RW, Tuder RM: Vascular endothelia growth factor in the lung. Am J Physiol Lung Cell Mol Physiol 2006, 290:L209-L22I

42. Kunig AM, Balasubramaniam V, Markham NE, Morgan D, Montgomery G, Grover TR, et al:: Recombinant human VEGF treatment enhances alveolarization after hyperoxic lung injury in neonatal rats. Am 」 Physiol Lung Cell Mol Physiol 2005, 289:L529-L535.

43. Kunig AM, Balasubramaniam V, Markham NE, Seedorf G, Gien J, Abman SH: Recombinant human VEGF treatment transiently increases lung edema but enhances lung structure after neonatal hyperoxia. Am J Physiol Lung Cell Mol Physiol 2006, 29I:LI068-LI078.

44. Thebaud B, Ladha F, Michelakis ED, Sawicka M, Thurston G, Eaton F, et al.: Vascular endothelial growth factor gene therapy increases survival, promotes lung angiogenesis, and prevents alveolar damage in hyperoxia-induced lung injury: evidence that angiogenesis participates in alveolarization. Circulation 2005, II 2:2477-2486.

45. Boerma M, Wees CG van der, Vrieling $H$, Svensson JP, Wondergem J, van der LA, et al.: Microarray analysis of gene expression profiles of cardiac myocytes and fibroblasts after mechanical stress, ionising or ultraviolet radiation. BMC Genomics 2005, 6(I):6.

46. Yamamoto K, Dang QN, Kennedy SP, Osathanondh R, Kelly RA, Lee $\mathrm{RT}$ : Induction of tenascin-C in cardiac myocytes by mechanical deformation. Role of reactive oxygen species. J Biol Chem 1999, 274:21840-21846.

47. Hemnes AR, Zaiman A, Champion HC: PDE5A inhibition attenuates bleomycin-induced pulmonary fibrosis and pulmonary hypertension through inhibition of ROS generation and RhoA/Rho kinase activation. Am J Physiol Lung Cell Mol Physiol 2008, 294:L24-L33.

48. Itoh T, Nagaya N, Fujii T, Iwase T, Nakanishi N, Hamada K, et al.: A combination of oral sildenafil and beraprost ameliorates pulmonary hypertension in rats. Am J Respir Crit Care Med 2004, 169:34-38.

49. Schermuly RT, Kreisselmeier KP, Ghofrani HA, Yilmaz H, Butrous G, Ermert L, et al.: Chronic sildenafil treatment inhibits monocrotaline-induced pulmonary hypertension in rats. Am J Respir Crit Care Med 2004, 169:39-45.

50. Nagendran J, Archer SL, Soliman D, Gurtu V, Moudgil R, Haromy A, et al:: Phosphodiesterase type $\mathbf{5}$ is highly expressed in the hypertrophied human right ventricle, and acute inhibition of phosphodiesterase type 5 improves contractility. Circulation 2007, I 1 6:238-248

5I. Felker GM, Petersen JW, Mark DB: Natriuretic peptides in the diagnosis and management of heart failure. CMA] 2006, I75:6II-6I7.

52. Yoshimura $M$, Yasue $H$, Okumura $K$, Ogawa $H$, Jougasaki $M$, Mukoyama $M$, et al.: Different secretion patterns of atrial natriuretic peptide and brain natriuretic peptide in patients with congestive heart failure. Circulation 1993, 87:464-469.

53. Potter LR, Abbey-Hosch S, Dickey DM: Natriuretic peptides, their receptors, and cyclic guanosine monophosphatedependent signaling functions. Endocr Rev 2006, 27:47-72.

54. Woodard GE, Rosado JA: Recent advances in natriuretic peptide research. J Cell Mol Med 2007, I I:1263-I27I. 